\title{
1 A coupled wave-hydrodynamic model of an atoll with 2 high friction: mechanisms for flow, connectivity, and 3 ecological implications
}

4 Justin S. Rogers* ${ }^{1}$, Stephen G. Monismith ${ }^{1}$, Oliver B. Fringer ${ }^{1}$, David A. Koweek ${ }^{2}$, and Robert 5 B. Dunbar ${ }^{2}$

6

7 1. Environmental Fluid Mechanics Laboratory, Stanford University, 473 Via Ortega, Y2E2 Rm 8 126, Stanford, California, 94305, USA

9 2. Department of Earth System Science, Stanford University, Stanford, California, 94305, USA

$10 *$ Corresponding author: jsrogers@stanford.edu

11

12

13

14

15

16 Prepared for Ocean Modelling

17

Rogers et al.

Oct 2016, Rev 2 


\section{Abstract}

We present a hydrodynamic analysis of an atoll system from modeling simulations using a coupled wave and three-dimensional hydrodynamic model (COAWST) applied to Palmyra Atoll in the Central Pacific. This is the first time the vortex force formalism has been applied in a highly frictional reef environment. The model results agree well with field observations considering the model complexity in terms of bathymetry, bottom roughness, and forcing (waves, wind, metrological, tides, regional boundary conditions), and open boundary conditions. At the atoll scale, strong regional flows create flow separation and a well-defined wake, similar to 2D flow past a cylinder. Circulation within the atoll is typically forced by waves and tides, with strong waves from the north driving flow from north to south across the atoll, and from east to west through the lagoon system. Bottom stress is significant for depths less than about $60 \mathrm{~m}$, and in addition to the model bathymetry, is important for correct representation of flow in the model. Connectivity within the atoll system shows that the general trends follow the mean flow paths. However, some connectivity exists between all regions of the atoll system due to nonlinear processes such as eddies and tidal phasing.

Moderate wave stress, short travel time (days since entering the reef system), and low

34 temperature appear to be the most ideal conditions for high coral cover at this site.

36 Keywords (6): coral reefs, hydrodynamics, surface water waves, temperature, atolls

37 Regional Terms: Pacific Ocean, Central Pacific, Northern Line Islands, Palmyra Atoll 


\section{Introduction}

41 Coral reefs provide a wide and varied habitat that supports some of the most diverse assemblages

42 of living organisms found anywhere on earth (Darwin, 1842). Coral reefs are critically important

43 for the hundreds of millions of people reliant on them for food, storm protection, and cultural

44 importance (Burke et al., 2011); yet they are under increased threat from climate change, ocean

45 acidification and a host of local stressors (Hoegh-Guldberg et al., 2007; Hughes et al., 2003;

46 Kleypas, 1999). Hydrodynamic flows influence the biological processes of coral reefs in several

47 ways (Chappell, 1980) and therefore understanding their characteristics in reef environments is

48 increasingly important (Monismith, 2007).

49 Hydrodynamic flows are the primary mechanism for dispersal and thus connectivity for small

50 larval species such as corals (Cowen and Sponaugle, 2009) and connectivity between reef

51 systems at inter-island scales using hydrodynamic models has been the subject of several studies

52 (Andréfouët et al., 2002; Jones et al., 2009; Roberts, 1997). At smaller scales, atolls represent a

53 geologic end ecologic member for reefs, and are common throughout the world's tropical oceans

54 (Riegl and Dodge, 2008). The distinctive geometry of exterior reefs and interior lagoon system

55 separated by a reef crest and reef flat with connecting channel systems is a unique feature which

56 creates different interconnected hydrodynamic regimes. Previous studies on atolls have focused

57 on portions of the system (Andréfouët et al., 2012, 2006; Dumas et al., 2012; Kench, 1998), but

58 to our knowledge, no studies exist studying interconnectivity within an atoll system.

59 Reefs are areas of high productivity because they are efficient at trapping and recycling nutrients,

60 thereby supporting both phytoplankton and zooplankton (Odum and Odum, 1955; Yahel et al.,

61 1998). Water motion appears to be beneficial to coral reefs through increasing the rates of

62 nutrient uptake, photosynthetic production and particulate capture (Atkinson and Bilger, 1992;

63 Carpenter et al., 1991; Genin et al., 2009). Reef-building corals have experienced global declines

64 resulting from bleaching events caused week to month-long warm-water exposure (Carpenter et

65 al., 2008; Hoegh-Guldberg et al., 2007; Hughes et al., 2003). However, corals in naturally warm

66 environments can exhibit enhanced resistance to bleaching at high temperatures through both

67 short-term acclimatory and longer-term adaptive acquisition of climate resistance (Palumbi et al., 
2014). Terrestrial systems often negatively impact reefs through increased nutrient loading and

69 sedimentation, among other factors (Acevedo et al., 1989; Buddemeier and Hopley, 1988;

70 Fabricius, 2005; Rogers, 1990); and the retention and removal of terrigenous sediment depends

71 on hydrodynamic processes (flushing rates, dilution), hydrology (e.g., accumulation and

72 groundwater discharge) as well as biological processes (Fabricius, 2005).

73 The hydrodynamics of reef systems are governed primarily by the forcing mechanisms that drive

74 flow, typically waves, tides, regional flow, wind, and buoyancy effects. These mechanisms have

75 different importance depending on the scale (Monismith, 2007). At the island scale, typically

76 kilometers, the flow is primarily governed by the interaction of the island with the large-scale

77 regional flow, tides, Coriolis effects, and buoyancy (Monismith, 2007). Depending on flow

78 conditions, vortices can be shed from local bathymetric features such as headlands, or from the

79 island itself (Arístegui et al., 1994; Wolanski et al., 1996).

80 At the reef scale, typically ten to hundreds of meters, waves have long been recognized as the 81 dominant forcing mechanism on many reefs (Callaghan et al., 2006; Kraines et al., 1998; Lowe

82 et al., 2009a; Lugo-Fernández et al., 2004; Munk and Sargent, 1954; Symonds et al., 1995).

83 Conceptually, wave dissipation from breaking or bottom friction increases the mean water level,

84 known as wave setup, establishing a pressure gradient that drives flow across the reef in the

85 direction of wave propagation (Lowe et al., 2009b; Munk and Sargent, 1954; Young, 1989). In

86 addition, tides can play a more direct role in driving circulation in larger and more enclosed

87 lagoons where the channels connecting the lagoon with the open ocean are relatively narrow, and

88 the constricted exchange of water between these lagoons and the open ocean can cause

89 significant phase lags between lagoon and offshore water levels (e.g., Dumas et al., 2012; Lowe

90 and Falter, 2015). Wind stresses often play only a minor role in driving the circulation of shallow

91 reefs; however, wind forcing can be important or even dominant in the circulation of deeper and

92 more isolated lagoons (Atkinson et al., 1981; Delesalle and Sournia, 1992; Douillet et al., 2001;

93 Lowe et al., 2009a). Finally, buoyancy forcing can drive reef circulation through either

94 temperature- or salinity-driven stratification, which may also be important in certain reef systems

95 (Hoeke et al., 2013; Monismith et al., 2006).

96 The classical dynamical basis by which waves drive flow is by changes to the waves from

97 physical processes such as shoaling, refraction, dissipation, etc., which create spatial gradients in

Rogers et al. Oct $2016, \operatorname{Rev} 2$ 
radiation stresses and impart a force in the momentum equation (Longuet-Higgins and Stewart, 1964). The radiation stress gradient can be recast as a vortex force in the full three-dimensional momentum equations, first proposed by Craik and Leibovich (1976) and developed more fully by Uchiyama et al. (2010). The vortex force is the interaction of the Stokes drift with flow vorticity, and is essential in the mechanism for Langmuir circulation. The vortex force formalism has recently been implemented in numerical models, and has shown increased skill over traditional radiation stress methods in predicting velocity profiles in conditions of coincident waves and currents (Kumar et al., 2015, 2012). While the vortex force formalism has shown good results in certain field conditions, it has not yet been implemented on coral reefs with high bottom drag and steep slopes.

Corals have irregular, branching morphologies and reef topography varies at scales ranging from centimeters to kilometers, therefore flow within these systems is complex (Rosman and Hench, 2011). In circulation models, variability in reef geometry occurs at scales smaller than the resolution of the computational grid; thus, drag due to the small scale geometry must be parameterized. On reefs, bottom friction is often a significant term in the momentum balance and the primary dissipation loss; and thus correct parameterization of the bottom drag is essential (Monismith, 2007).

Understanding the hydrodynamics across a range of spatial and temporal scales is necessary for understanding coral reef ecosystem function since critical ecosystem processes such as larval dispersal, and hence genetic connectivity, are heavily dependent upon atoll hydrodynamics. Thus the potential of coral reefs to withstand a warmer and more acidic future is partly informed by better understanding the hydrodynamics of atoll-wide coral reef ecosystems. The goals of this study were to apply a hydrodynamic model using the vortex force implementation in a high frictional reef environment and validated through extensive field observations to better understand the processes, timescales, and spatial scales that govern the hydrodynamics and connectivity on a model atoll. We first assess the performance of the hydrodynamic model and examine the effects of different forcing mechanisms in driving flow at the scale of the atoll itself, as well as circulation within the atoll system. We then investigate the interconnectivity of the atoll and address the role of hydrodynamics in shaping its ecological community structure. 


\section{Methods and Study Site}

\section{$128 \quad 2.1 \quad$ Field Study Site and Observations}

129 Numerous small islands and atolls dot the Central Pacific, including Palmyra Atoll, in the

130 Northern Line Islands. The Northern Line Islands in the central equatorial Pacific are of

131 significant ecological interest (Sandin et al., 2008; Stevenson et al., 2007). Palmyra Atoll in

132 particular because of its status as a National Wildlife Refuge ( $5^{\circ} 52^{\prime} \mathrm{N}, 162^{\circ} 05^{\prime} \mathrm{W}$ ) (Figure

133 1a,b), is thought to represent a reef with little anthropogenic degradation and abundant calcifiers.

134 Palmyra's exposed reef tracts (outside of the lagoons) contain abundant and diverse calcifiers,

135 namely hard corals and crustose coralline algae (Williams et al., 2013) with relatively high

136 community production and calcification rates (Koweek et al., 2015b). Thus, characterizing the

137 hydrodynamics in this isolated atoll system with an intact exterior reef structure and highly

138 frictional environment is of interest (Monismith et al., 2015; Rogers, 2015; Rogers et al., 2016a,

$1392016 b, 2015)$.

140 The atoll consists of a forereef, reef crest and shallow back reef region on both its northern and

141 southern sides, while the western and eastern edges are dominated by open terraces of 5 to $20 \mathrm{~m}$

142 depth with abundant corals (Figure 1). The forereefs are characterized by high percentages of

143 live stony coral cover (Figure 1c,e), and typical spur and groove formations (Rogers et al., 2015).

144 Near the reef crest where the surfzone is found, the substrate largely consists of rubble whereas

145 further inshore, larger corals are common on the back reef. The open terraces are typically

146 characterized by high live coral cover with high rugosity and complex bathymetry (Figure 1d,e),

147 while lagoonal areas typically exhibit soft sediment substrates (Williams et al., 2013).

148 Field observations of waves, currents, temperature were conducted on the atoll from 2012 to

1492014 (Figure 2) with additional details and results in Rogers (2015), Rogers et al. (2016a), and

150 Rogers et al. (2016b). The wave climate is seasonal, dominated by storm waves (1-3 m) from the

151 north in the northern hemisphere winter, and storm waves (1-2 m) from the south in the southern

152 hemisphere winter (Figure 2a) (Rogers et al., 2016a). The tidal range is typically $0.8 \mathrm{~m}$, with

153 seasonal long-term sea level fluctuations of $0.2 \mathrm{~m}$ (Figure $2 \mathrm{~b}$ ). The winds on the atoll are

154 dominated by the northeasterly trade winds for much of the year, and are strongest in February 
155 through May, typically near 5 m/s (Figure 2c) (Maragos et al., 2008; Rogers, 2015). The atoll is

156 generally within the North Equatorial Counter Current (NECC), which flows primarily to the 157 east at typically 0.2 to $0.8 \mathrm{~m} / \mathrm{s}$ from August to January, and is weak the rest of the year (Figure 158 2d) (Hsin and Qiu, 2012; Maragos et al., 2008), while large scale tropical instability waves are 159 common in this region (Stevenson et al., 2015). Weekly average water temperatures on the atoll

160 are typically 27 to $30{ }^{\circ} \mathrm{C}$ and vary seasonally, while $95 \%$ of local diurnal temperature

161 fluctuations are typically within $1{ }^{\circ} \mathrm{C}$ of the mean (Figure 2e) (Gardner et al., 2014b). Low pass

162 filtering for these results and modeling results in the following sections was done using a spectral 163 cutoff filter.

\section{$164 \quad 2.2$ Coupled Wave-Hydrodynamic Model}

165 The Coupled-Ocean-Atmosphere-Wave-Sediment Transport (COAWST) program (Warner et 166 al., 2010) was used to model the atoll. Only the ocean (Regional Ocean Modeling System 167 ROMS) and wave (Simulating Waves in the Nearshore - SWAN) modules were used in this 168 study. The SWAN wave component of the model (Booij et al., 1999) contains a modified wave 169 bottom friction formulation (Rogers et al., 2016a) to account for the very high wave friction 170 factors from field observations (Monismith et al., 2015).

171 ROMS is a three-dimensional, free surface, topography following numerical model, which solves 172 finite difference approximation of Reynolds Averaged Navier Stokes equations using hydrostatic 173 and Boussinesq approximation with a split explicit time stepping algorithm (Haidvogel et al., 174 2008; Shchepetkin and McWilliams, 2009, 2005). The vortex force formalism expresses the 175 Navier Stokes equations to include the effects of waves (Uchiyama et al., 2010),

$$
\begin{aligned}
\frac{\partial \boldsymbol{u}}{\partial t}+\left(\boldsymbol{u} \cdot \nabla_{\perp}\right) \boldsymbol{u} & +w \frac{\partial \boldsymbol{u}}{\partial z}+f \hat{z} \times \boldsymbol{u}+\nabla_{\perp} \varphi-\boldsymbol{F}-\boldsymbol{D}+\frac{\partial}{\partial z}\left(\overline{u^{\prime} w^{\prime}}-v \frac{\partial \boldsymbol{u}}{\partial z}\right) \\
= & -\nabla_{\perp} \kappa+\boldsymbol{J}+\boldsymbol{F}^{\boldsymbol{w}},
\end{aligned}
$$

176 where $(\boldsymbol{u}, w)$ are the Eulerian mean velocities, $z$ is the vertical coordinate, $f$ is the Coriolis

177 parameter, $\varphi$ is the dynamic pressure (normalized by density), $\boldsymbol{F}$ is the non-wave, non-

178 conservative force, $\boldsymbol{D}$ is the diffusive terms (viscosity and diffusion), $v$ is the molecular viscosity, $179 \kappa$ is the lower order Bernoulli head, $\boldsymbol{F}^{w}$ is the sum of momentum flux due to all non-conservative 180 wave forces, and $\boldsymbol{J}$ is the horizontal vortex force, 


$$
\boldsymbol{J}=-\hat{z} \times \boldsymbol{u}^{s t}\left[\left(\hat{z} \cdot \nabla_{\perp} \times \boldsymbol{u}\right)+f\right]-w^{s t} \frac{\partial \boldsymbol{u}}{\partial z}
$$

181 where $\left(\boldsymbol{u}^{s t}, w^{s t}\right)$ is the Stokes drift.

182 The vortex force formalism is implemented in ROMS which solves for the Eulerian mean 183 velocities and has shown improved skill in computed wave-driven velocities over the more 184 traditional radiation stress gradient formulation (Kumar et al., 2012). The significant terms in the 185 three dimensional momentum equation, are then acceleration (ACC), horizontal advection (HA), 186 vertical advection (VA), Coriolis (COR), Stokes-Coriolis (StCOR), pressure gradient (PG), 187 horizontal vortex force (HVF), non-wave body force (BF), wave breaking acceleration (BA), 188 wave roller acceleration (RA), bottom streaming (BtSt), surface streaming (SuSt), horizontal 189 mixing (HM), vertical mixing (VM), and curvilinear grid (FCurv). Vertical integration of the 190 three dimensional equations, applying surface and bottom boundary conditions, assuming a 191 rectangular grid, and ignoring wave streaming and Stokes-Coriolis effects gives the two192 dimensional momentum equation (Kumar et al., 2012),

$$
\mathrm{ACC}+\mathrm{HA}+\mathrm{COR}=\mathrm{PG}+\mathrm{HVF}+\mathrm{Bstr}+\mathrm{Sstr}+[\mathrm{BA}+\mathrm{RA}]+\mathrm{HM}
$$

194 where bottom stress (Bstr) and surface stress (Sst) arise from the boundary conditions.

195 The model grid consists of a rectangular $(x, y)$ grid covering 34.1 by $14.1 \mathrm{~km}$ at $50 \mathrm{~m}$ grid 196 resolution, extending from -162.2387 to $-161.9313^{\circ} \mathrm{W}$ and 5.8189 to $5.9470{ }^{\circ} \mathrm{N}$ (Figure $3 \mathrm{a}, \mathrm{b}$ ).

197 Vertical resolution consists of 20 vertical layers in sigma-coordinates (3.8M total grid cells). The 198 data used for the model bathymetry is based on NOAA ship-based multi-beam bathymetry for 199 depths greater than $10 \mathrm{~m}$, and linear regression of $5 \mathrm{~m}$ grid IKONOS multispectral data for 200 shallow depths [Pacific Islands Benthic Habitat Mapping Center, 201 http://www.soest.hawaii.edu/pibhmc]. Grid bathymetry is interpolated from data sources and 202 smoothed using a Shapiro filter until the appropriate grid stiffness parameters were met 203 (Shchepetkin and McWilliams, 2003). A relatively small model domain is adequate for this 204 setting because the atoll is isolated from other bathymetric features and the large scale flows 205 generally exit the model domain. The reef crest is explicitly included in the grid based on field 206 measurements and aerial images, and to reduce the complexity of the model, max depth was 207 limited to $200 \mathrm{~m}$, essentially the upper ocean mixed layer. Mapping of the dominant biological 
cover (Figure 1e) was obtained from NOAA NCCOS Benthic Habitat Mapping

209 (http://ccma.nos.noaa.gov/ecosystems/coralreef/palmyra), and in conjunction with computed

210 values of bottom roughness heights $z_{0}$ across the atoll (Rogers, 2015) are used to infer a spatially

211 variable $z_{0}$ over the model domain (Figure 3c). A consistent grain size grid is input to both the

212 ROMS and SWAN models. For the ROMS model, the Sherwood, Signell, Warner bottom

213 boundary layer closure is employed to include both wave and mean current bottom stress

214 (Warner et al., 2010). The SWAN wave model uses a revised friction formulation which

215 correctly parameterizes the high wave friction on the atoll, as well as breaking coefficient values

216 obtained from site data (Rogers et al., 2016a).

217 Initial conditions and lateral boundary conditions for velocity $\boldsymbol{u}$, temperature $T$, salinity $S$, and

218 free surface height $\zeta$, are interpolated from the National Ocean Partnership Program (NOPP)'s

219 HYbrid Coordinate Ocean Model (HYCOM) global ocean model (http://hycom.org) (Figure 3a).

220 The ROMS open boundary conditions are Chapman for the free surface, Flather for 2D

221 momentum, radiative with nudging for 3D momentum $T$, and $S$, and gradient for TKE similar to

222 Kumar et al. (2015). Initial conditions for $T$ and $S$ within the lagoon system are taken from the

223 WL temperature mooring observations, and annual CTD casts within the lagoon. In order that

224 broad regional temperatures are similar between the model and field observations, the HYCOM

225 initial (outside the lagoon interior) and boundary condition temperatures are adjusted by a

226 spatially constant offset such that two-week average of the spatially averaged temperature of the

227 upper $50 \mathrm{~m}$ depth from the HYCOM model match the two-week average of field observations on

228 the atoll exterior forereefs. This is similar to climatology routines employed in regional models,

229 and offsets were typically less than a degree C. Tidal constituents are derived from the 2011

230 Oregon State University Pacific Ocean 1/12 ${ }^{\circ}$ Tidal Atlas (OTIS) (Egbert and Erofeeva, 2002).

231 The generic length scale turbulence scheme is employed with coefficients consistent with the $k-\varepsilon$

232 model (Warner et al., 2005).

233 Boundary conditions for the SWAN model are taken from measured wave height and period on

234 the north (FR9) and south (FR5) of the atoll, corrected for changes to refraction, shoaling, and

235 travel time from the measured location to the model boundary conditions, with wave angle taken

236 from the NOAA Wave Watch III Hawaii Model results, and directional waves resolution is $5^{\circ}$

237 (Rogers et al., 2016a). 
238 Atmospheric winds, shortwave and longwave radiation, rainfall, air temperature, relative

239 humidity, and air pressure were included in the model and taken from a weather station on the 240 atoll (Figure 1b) and implemented using the bulk fluxes model in ROMS. For periods of time 241 when data was not available from on island measurements, atmospheric forcing was interpolated 242 from NASA's Modern-Era Retrospective Analysis for Research and Applications (MERRA) 243 global atmospheric model (http://disc.gsfc.nasa.gov). Notably, these periods include wind (prior 244 to Sep-2013), rainfall (after Dec-2013), and longwave radiation (prior to Sep-2013).

245 Four separate periods of simulation were modeled using the COAWST model. Computations 246 were run in parallel on 64 AMD Opteron $(2.4 \mathrm{GHz})$ cores and due to processing time limitations, 247 runs were limited to 14 day periods, which typically took $7500 \mathrm{cpu}$ hours each. The first 248 simulation, referred to as Run 1, simulates 3-Nov to 17-Nov 2012, and is a period of relatively 249 average conditions with waves from the north $\left(1.19 \mathrm{~m} H_{s}\right)$, eastern regional currents at $0.6 \mathrm{~m} / \mathrm{s}$, 250 light winds, and average temperatures (Figure 2). Runs 2 through 4 represent periods of variation 251 in forcing parameters such as very strong northern waves (Run 2), strong southern waves (Run 252 3), weak waves (Run 4), weak regional flows (Run 2), and different direction of regional flow 253 (Run 4) (Figure 2).

254 The offshore travel time, or age represents the amount of time an individual fluid parcel or 255 particle has spent inside of a domain since it entered a boundary (Monsen et al., 2002), here 256 taken as the $100 \mathrm{~m}$ bathymetric depth contour. Lagrangian floats were released for each 257 simulation starting approximately 2 days after model initialization, with some simulations 258 varying this time to vary the tidal cycle of release. Here, Lagrangian refers to the floats with 259 neutral density following the mean flows within the ROMS model, (which are essentially 260 Eulerian) but do not include the effects of Stokes drift. This approximation may underestimate 261 transport very near the surface when Stokes drift from waves is strong, but is likely reasonable 262 otherwise. 22,447 floats were released within the model domain in and around the atoll, spaced 263 evenly between the bottom, mid and top of the water column. Travel time was computed for each 264 float as the time since the float crossed the $100 \mathrm{~m}$ bathymetric contour into the atoll. Results of 265 travel time for all particle tracks were interpolated to a fine scale $10 \mathrm{~m}$ grid and then down 266 sampled to the model grid using a median filter. Age is the converse of the commonly reported 267 Lagrangian residence time, defined as a time taken for a parcel of fluid to leave a boundary 
268 (Monsen et al., 2002). For this system, travel time is a more relevant metric since we are most 269 interested in how offshore waters are modified within the atoll system by interactions with 270 organisms, terrestrial runoff, and the substrate.

\section{Results}

\subsection{Model Data Comparison}

273 Four separate periods of simulation (Runs 1 - 4) were modeled to characterize different forcing

274 conditions. Run 1 is used for validation because it is the period of average conditions with 275 substantial coincident field data (Figure 2) (Rogers, 2015). The model results compare well to 276 measured field observations for free surface height $\zeta$, depth averaged alongshore flow $U_{A S}$, depth 277 averaged cross-shore flow $U_{C S}$, and bottom temperature $T_{b}$ at three selected sites, and for velocity 278 and temperature in both 36-hour subtidal filtered $\left(\overline{U_{A S}}, \overline{U_{C S}}, \overline{T_{b}}\right)$ and high frequency variability $279\left(U_{A S}^{\prime}, U_{C S}^{\prime}, T_{b}^{\prime}\right)$ (Figure 4). Additionally, the significant wave height has been previously shown to 280 have good agreement between the model and field observations (Rogers et al., 2016a).

281 To compare model predictions of a given variable of interest $X_{\text {model }}$ to the observations $X_{o b s}$ in 282 reef environments (Lowe et al., 2009a; Rogers et al., 2016a), we used a quantitative measure of 283 model skill (Willmott, 1982),

$$
\text { Skill }=1-\frac{\sum\left(X_{\text {model }}-X_{o b s}\right)^{2}}{\sum\left(\left|X_{\text {model }}-\overline{X_{o b s}}\right|+\left|X_{o b s}-\overline{X_{o b s}}\right|\right)^{2}}
$$

284 where perfect agreement between model results and observations will yield a skill of one and 285 complete disagreement yields a skill of zero. Over all available field data sites, average model 286 skill for $\zeta$ is 0.98 , for $\bar{U}$ is 0.36 , for $U^{\prime}$ is 0.46 , for $\overline{T_{b}}$ is 0.73 and $T_{b}^{\prime}$ is 0.58 (Table 1 ), with more 287 detailed validation information in Rogers (2015) and Rogers et al. (2016a). Overall, after a 288 period of about 2 days for model spin up, the COAWST model results for $\zeta, H_{s}, U_{A S}, U_{C S}$, and $T_{b}$ 289 reasonably represent the mean and high frequency variability at each site in simulating the field 290 scale flows observed on the atoll. 


\subsection{Tides}

292 The open boundaries of the model are forced with tidal information from the OTIS database. On

293 the atoll exterior forereefs and lagoon entrance channel, tidal amplitude is in excellent agreement

294 and tidal phase is reasonably in agreement (Figure 5). Within the innermost lagoon (East

295 Lagoon), the model over predicts the tidal amplitude and under predicts the phase compared to

296 the observations (Figure 5). This discrepancy is likely due to inadequate resolution of the

297 openings to the East Lagoon inlets which on the atoll vary from 10 to $100 \mathrm{~m}$ width whereas the

298 grid scale is $50 \mathrm{~m}$. Thus, the OTIS database does well represent the tidal fluctuations on the

299 exterior of the atoll but the East Lagoon is more open to exchange in the model and tidal

300 exchange is not sufficiently damped.

\section{$301 \quad 3.3$ Vertical Structure of Velocity and Temperature}

302 The root mean square (rms) vertical velocity profiles on the forereef are reasonably predicted in 303 the cross shore direction, while in the alongshore direction the general logarithmic profile shape 304 is correct, and the model reasonably predicts the magnitude (Figure 6a,b). In the channel, both 305 cross- and alongshore rms velocity profiles $\bar{u}_{r m s}$, are in good agreement with field observations

306 (Figure 6c). The West Lagoon did not have field observations, but the model results show an rms 307 profile consistent with wind driven surface shear (Figure 6d).

308 The average temperature profiles $\bar{T}$, are in good agreement at the Forereef and Channel sites 309 (Figure 6e,f,g). In the West Lagoon, $\bar{T}$ is in good agreement in the upper $25 \mathrm{~m}$ mixed layer, but 310 the model significantly over predicts $\bar{T}$ in the lower $25 \mathrm{~m}$ (Figure $6 \mathrm{~h}$ ).

\section{Discussion}

\section{$312 \quad 4.1$ Recipes for Successful Simulations in an Atoll System}

313 The model skill is excellent for the free surface and waves, and the model reasonably reproduces

314 the mean and overall variability of velocities and temperature, which is typical of field scale

315 models (Kumar et al., 2015). Differences in modeled and observed subtidal velocities on the

316 forereef are likely influenced by the incoming boundary conditions from the HYCOM model,

317 which cannot explicitly model mesoscale and submesoscale eddies which are stochastic in Rogers et al. Oct 2016, Rev 2 
nature. Considering the model complexity due to variable bathymetry and bottom roughness,

319 multiple types of forcing (waves, wind, meteorological, tides, regional boundary conditions), and

320 open boundary conditions from a global model, the results for depth averaged quantities, tides,

321 and vertical structure are in good agreement with the field observations.

322 For predicting local flows on the atoll, bathymetry is a critical input parameter, especially in

323 areas of strong hydrodynamic control such as the reef crest, channel, and lagoon inlets.

324 Additionally, a critical factor is smoothing the grid sufficiently to achieve model stability, while

325 still maintaining realistic geometry. Finally, because bottom stress is a significant term in the

326 momentum balance for areas of shallow depth on the atoll, correct parameterization of bottom

327 roughness is essential (Hench et al., 2008) and is achieved here through site observations of

328 roughness and extended spatially through habitat mapping.

329 Areas of the model which are not well resolved due to the grid resolution include the East

330 Lagoon inlets, which allow higher exchange through this lagoon in the model. This could be

331 improved through higher grid resolution in these areas or parameterization of this subgridscale

332 process such as weir flow or increased drag.

333 The average temperature profiles are in good agreement at the Forereef and Channel sites; the

334 means are in agreement likely due to the offset adjustment of boundary condition temperatures

335 from the HYCOM model. However, in the West Lagoon, the model significantly over predicts

336 temperature in the lower $25 \mathrm{~m}$. Since the model was initiated with realistic $T$ and $S$ profiles, the

337 reason for this deviation is likely areas of too much mixing in the deep lagoon created by small

$338 O(0.1 \mathrm{~cm} / \mathrm{s})$ spurious vertical velocities along the sides of the lagoons, which have relatively

339 steep slopes and low background velocities, and issue previously noted in other studies using

340 sigma coordinates (Shchepetkin and McWilliams, 2009, 2005). While these effects also exist

341 along the forereef slopes, the background currents exhibit much larger values of $O(10 \mathrm{~cm} / \mathrm{s})$ and

342 thus have little effect on the mixing. Since the contribution of the deep lagoons to transport is

343 small, the effect on the model results in the domain outside the deep lagoons is therefore small,

344 and model results are in good agreement with the observations. However, the results for

345 temperature and exchange in the deep lagoons are likely inaccurate. Future models investigating

346 similar low-energy environments should consider this effect if the effects of mixing are

347 important. This overmixing could be improved through increased smoothing of the bathymetry,

Rogers et al. $\quad$ Oct $2016, \operatorname{Rev} 2$ 
use of a z-level model (instead of sigma level), and/or a nonhydrostatic model e.g. SUNTANS

349 (Fringer et al., 2006). Outside of these regions, the model temperature profiles are in good 350 agreement with field observations.

351 Two alternate ways of implementing the 3D wave forcing into the Navier Stokes equations

352 include the traditional radiation stress gradient (Mellor, 2011, 2008), and vortex force formalism

353 (Uchiyama et al., 2010). Several runs were conducted using the radiation stress method; these

354 simulations yielded unrealistically high velocities near the surface by up to a factor of three. This

355 issue was most apparent in locations with shoaling, non-breaking waves; an issue also noted by

356 Kumar et al. (2011). In contrast, implementation of the vortex force method for this model

357 (Uchiyama et al., 2010) produces realistic vertical velocity profiles and mean flows (Figure 4 and

358 Figure 6). Thus the vortex force method appears to be the preferred method for modeling the

359 effect of waves on currents in three-dimensions in this environment.

\section{$360 \quad 4.2$ Interaction of Atoll with Regional Flow}

361 In the presence of a strong easterly regional current on 06-Nov-2012, the atoll creates flow

362 separation and a large wake, which extends a significant distance offshore from the forereef, with 363 shed vortices clearly visible, while in the presence of a northerly regional current on 29-Sep-

364 2013, the wake is less clearly defined but with vortices still present (Figure 7). In both cases, 365 vortices are shed from leading edge of the separated region which propagate downstream in the 366 mean flow. At times, these vortices migrate towards the atoll and interact with the forereef, or 367 alternately may spin off into the open ocean. There are also some locations of persistent 368 circulation forced by irregularities in the atoll shape, most notably on the southwest corner of the 369 atoll.

370 The primary two-dimensional momentum balance at the atoll scale (offshore) is between 371 acceleration (ACC), pressure gradient (PG), and horizontal advection (HA) (Figure 8),

$$
\mathrm{ACC}+\mathrm{HA}=\mathrm{PG}
$$

373 The model includes only the upper $200 \mathrm{~m}$, and is essentially modeling the upper mixed layer, the 374 depth of which is set by the regional stratification. Thus the flow dynamics are primarily 375 governed by the forcing from the regional flow and its interaction with the geometry of the atoll. 
376 Flow around the atoll appears similar in nature to 2D flow past a cylinder, where the Reynolds 377 number governs the flow. For island wakes, Wolanski et al. (1996) proposed an island wake 378 parameter $P$, essentially the Reynolds number times the aspect ratio,

$$
P=\left(\frac{U L}{K_{z}}\right)\left(\frac{H}{L}\right)^{2}
$$

379 where $U$ is the free stream velocity, $L$ is the island horizontal scale, $H$ is the island vertical scale 380 and $K_{z}$ is the vertical mixing viscosity. Based on laboratory data, for $P<1$, there is no wake, for $3811<P<10$ the wake is stable, and for $P>10$ vortices are shed from the island (Wolanski et al., 382 1996). For Palmyra, we assume $L$ varies from 4 to $19 \mathrm{~km}$ depending on flow direction, $U$ varies 383 from 0.1 to $0.8 \mathrm{~m} / \mathrm{s}$, the upper mixed layer depth $H$ is typically 100 to $200 \mathrm{~m}$, and $K_{z}$ is typically 3840.004 to $0.01 \mathrm{~m}^{2} / \mathrm{s}$ in the model. With these assumptions, $P$ would range from 5 to 2000 , within 385 the stable wake regime for some conditions, but typically within the unstable vortex shedding 386 regime, consistent with modeling results. For certain conditions such as very low free stream 387 velocity, high mixing, or shallow mixed layer depth, the wake can become stable, an effect 388 which could be studied further. In addition, this simplified model ignores stratification within the upper mixed layer, Coriolis effects, sloping island walls, and bottom stress, all of which could be 390 considered.

\section{$391 \quad 4.3$ Circulation within Atoll}

392 To explain the circulation patterns and dominant forcing mechanisms at smaller scales within the 393 atoll, we look at the depth average momentum budget. Note that within this section, total 394 momentum (i.e. $|\mathrm{HA}|$ ) is used is used for simplicity instead of the individual vector components, 395 and relative fraction values are the average fraction of total momentum budget (i.e. for term $\left.396 \quad \bar{X}_{l}=\overline{\left|X_{l}\right| / \sum_{l}\left|X_{l}\right|}\right)$.

397 On the atoll, the significant terms are ACC, HA, PG, HVF, Bstr, Str, and RA depending on the 398 location (Figure 8). The COR and HM terms are generally not important in driving the 2D flow. 399 The importance of the significant terms is strongly dependent on depth and hydrodynamic 400 regime. The ACC and HS terms are important at most depths greater than $5 \mathrm{~m}$, and the PG term 401 is important at all points in the domain (Figure 8a,b,d). The Bstr term from the rough reef is 402 important at all depths less than $60 \mathrm{~m}$, while the Str term from wind forcing is important within 
403 the interior lagoons and shallow backreefs (Figure 8f,g). Due to the effect of wave forcing, the 404 RA term is important only within the surf zone, and the HVF is only weakly important in the 405 shoaling region before breaking (Figure 8e,h). Using these results, the 2D momentum balances in 406 the various hydrodynamic regimes within the atoll can be approximated.

407 On the forereefs and reef terraces with depths between 5 and $60 \mathrm{~m}$ where waves are not often 408 breaking, the balance can be approximated as,

$$
\mathrm{ACC}+\mathrm{HA}=\mathrm{PG}+\mathrm{HVF}+\mathrm{Bstr}+\mathrm{Sstr}
$$

410 and forcing from tidal flow, regional currents, waves and winds can all be important. However, 411 the Sstr and HVF terms are generally less than $10 \%$ of the overall budget.

412 On the forereef in depths less than $5 \mathrm{~m}$, typically within the surfzone, the balance can be 413 classically approximated as,

$$
0=\mathrm{PG}+\mathrm{Bstr}+\mathrm{RA},
$$

415 and consequently, tides creating large scale PG and breaking waves creating RA are the primary 416 driver of flow in this regime. Here, the roller model (RA) accounts for the largest forcing from 417 waves, while the vortex forcing (HVF) is relatively weak.

418 On the shallow back reefs with depths less than $5 \mathrm{~m}$, the balance can be approximated as,

$$
0=\mathrm{PG}+\text { Bsrt }+ \text { Sstr }
$$

420 and within the interior lagoons with depth between 5 and $60 \mathrm{~m}$, the balance is approximated as,

$$
\mathrm{ACC}+\mathrm{HA}=\mathrm{PG}+\mathrm{Sstr}
$$

422 Forcing is primarily from winds on the back reef and lagoons, but pressure gradients generated 423 by other processes such as tides and waves can also drive the flow.

424 Due to the rough and rugose reef, bottom stresses (Bstr) are important at all locations less than $42560 \mathrm{~m}$ depth on the atoll. Correct parameterization of this effect is critical to accurately modeling 426 flow. For this study, extensive field data at multiple sites allowed for calculation of roughness 427 values (Rogers, 2015), which are consistent with results from other reefs (Lentz et al., 2016; 
428 Rosman and Hench, 2011). However, the theory is currently not well developed for selection of 429 roughness values a priori from high resolution bathymetric data or other site mapping, and could 430 be considered for future work.

431 Offshore wave height and direction have a significant effect on the setup and flow within the 432 atoll interior. Waves are sheltered on the lee of atoll and focused on the exterior edges (Figure 433 9a,b). Mean free surface setup is highest along the shallow reef flats on the side of the atoll with 434 highest wave height (Figure 9c,d). Due to these free surface differences, pressure gradients drive 435 flow in the direction of the dominant waves over the reef crest, easterly through the lagoon 436 system, and variably on the eastern and western terraces (Figure 9e,f). As expected, surface 437 water temperature is lowest during the night (Figure 9g), and highest during the day (Figure 9h) 438 on the shallow interior areas, and more stable in the offshore waters.

439 Tides can modulate the wave-driven flow in shallow areas (Koweek et al., 2015a; Monismith et 440 al., 2013). At high tide, waves drive flow over the reef crest (Figure 10a), while at low tide, the 441 reef crest is exposed and while the wave forcing is nearly the same, the waves in this case drive 442 an alongshore flow to the northwest and no flow over the crest (Figure 10b). The net flow over 443 the reef crest $q_{\text {crest }}$ generally increases with increasing offshore wave energy flux $\mathcal{F}_{\text {wave }}$, but tides 444 modulate this flow such that for a given incoming $\mathcal{F}_{\text {wave }}, q_{\text {crest }}$ is much higher at high tide than 445 low tide (Figure 10c). A simple model of setup from breaking in the surfzone and friction446 pressure gradient on the backreef predicts that $q_{\text {crest }}=a \mathcal{F}_{\text {wave }}^{1 / 5}+b$ (Monismith et al., 2013), 447 which is a reasonable fit to the model results with $\mathrm{r}^{2}=0.61$ for $\mathrm{a}=0.0855$ and $\mathrm{b}=-0.435$.

448 Average bottom wave stress is highest within the shoaling region and surfzone of the forereef 449 (Figure 11a). Here, the mean value of the top $2 \%$ of near-bed wave velocities squared is 450 employed, a proxy for bottom stress independent of the assumed bottom friction (Rogers et al., 451 2016a). The net long term average circulation shows flow going over the reef crest into the 452 interior of the atoll and in general from east to west within the interior lagoon (Figure 11b) 453 (average from the four two-week simulations). On the western exterior terraces and forereefs, 454 flow is primarily driven to the east by the regional flow NECC (Figure 11b). However, 455 individual particle tracks can follow very different flow paths than the mean flows and divergent 456 path from each other due to nonlinear processes such as eddies and dispersion (Figure 12). For 
example, particles from the far western terrace (WT W) travel around the atoll to the east

458 predominantly with the mean flow (Figure 12a). However, particles released on the southwest

459 forereef (FR SW FR3) go predominantly east in the mean flow, but some circle around into the

460 lagoon, while others cross the eastern terrace to the north. Particles released from within the

461 interior lagoon (EL2) follow many divergent paths through the lagoon interior, to the north or

462 south forereefs (Figure 12h). These results are only a sample from one model run; different mean

463 flow patterns produce different particle tracks.

464 Using these float tracks over all four runs to calculate travel time from offshore to a point on the 465 atoll (age), the average age is less than 20 hours on the exterior reefs, and up to 120 hours in the 466 interior lagoons (Figure 11c). Due to the increased mixing in the lagoons from spurious vertical 467 velocities, these results in the lagoons are likely representative of the upper mixed layer. The 468 deep lagoon areas greater than $20 \mathrm{~m}$ depth likely have flushing times of 1 to 3 years based on 469 dissolved oxygen profiles (Gardner et al., 2014a). Average high temperatures $\bar{T}_{b 90}$ (average of 470 top $90^{\text {th }}$ percentile of weekly average $T_{b}$ ) are lowest on the exterior reefs and deep lagoons and 471 highest on shallow reef flats with low exchange (Figure 11d).

472 While the analysis of depth-averaged circulation likely captures the primary mechanisms for 473 flow, density-driven flows may also be important on the atoll. The lagoon system is stratified, 474 and the channel velocity profile and cross-shore flow on the forereefs shows likely evidence of 475 classic baroclinic exchange flow (Rogers et al., 2016b). Shallow water on the reef flats is likely 476 saltier due to differential evaporation and with cooling at night, this water could form bottom 477 density currents which propagate into the interior lagoons or along the exterior forereefs. Thus, 478 further inquiry into density driven flows at the site is warranted.

\subsection{Ecological Implications and Connectivity}

480 One of the primary motivations for undertaking this study is to better understand the role of 481 hydrodynamics in establishing ecological connectivity on the atoll. The Lagrangian connectivity 482 is obtained from the float track model results (Figure 12) and summarized in Figure 13a. Overall, 483 the atoll is well connected between regions, and the dominant regions serving as a source are the 484 West Lagoon, Channel and nearby reefs (Figure 13a,b). Within the atoll interior, primary 485 connectivity is east to west, while on the exterior of the atoll primary connectivity is west to east, 
consistent with mean flow paths (Figure 13b). However, limited connectivity occurs between all

487 regions due to tidal phasing, large scale vortices, and other nonlinear effects where individual

488 floats can follow independent tracks which are quite different than the mean flow (Figure 12).

489 Thus it appears possible for a parcel of water to travel between any region of the atoll for a given 490 set of flow conditions.

491 It should be noted that this study only considered the connectivity of water parcels passing over 492 each region. Thus, while a parcel of water may pass over a region, it may not be in contact with 493 the bottom, an aspect of the particle trajectory which is of ecological importance for some 494 organisms (e.g.) larval organisms trying to settle on the substrate. Additionally, the Lagrangian 495 floats in these simulations are neutrally carried by the mean velocities, and do not exhibit any 496 swimming patterns, such as exhibited by many larvae (Cowen and Sponaugle, 2009). Additional 497 work could include explicitly modeling different types of larval behavior within the atoll system.

498 Hydrodynamic properties of interest to coral reef ecosystems include wave stress, light, mean 499 flows, offshore travel time (age), and temperatures, among others. On Palmyra, depth (a proxy 500 for light) has been previously shown to have only a limited effect on coral cover (Rogers et al., 501 2016a). The limited effect of light is likely because in this clear water low sun angle setting, light 502 zonation is deeper than the extent of benthic mapping (<20 $\mathrm{m}$ depth) (Chappell, 1980).

503 To evaluate the effect of wave stress, mean flows, age, and temperatures on coral cover, the 504 cumulative probability is used (Figure 14). Each model grid cell has average hydrodynamic 505 results for average near bottom high wave stress $\overline{u_{b w}^{2}}$, average near bed velocity $\overline{\left|u_{b}\right|}$, mean 506 travel time (age), and mean of $90^{\text {th }}$ percentile of weekly average temperature $\bar{T}_{b 90}$ (Figure 11); 507 and also a biological cover type (Figure 1e). The results for each biological cover classification 508 over the entire grid (i.e. Coral $0<10 \%$ ) are then presented as the cumulative probability of the 509 hydrodynamic properties. This allows evaluation of how, on average, hydrodynamic properties 510 are distributed in a given biological cover type. If we assume the reef is generally stable, this 511 suggests how hydrodynamic properties may or may not be influencing the reef.

512 Water motion appears to be beneficial to coral reefs through increasing the rates of nutrient 513 uptake, photosynthetic production and particulate capture (Atkinson and Bilger, 1992; Carpenter 514 et al., 1991; Genin et al., 2009). However, large forces from strong wave motion can subject 
515 corals to breakage resulting in trimming or reconfiguration of the reef (Storlazzi et al., 2005). On

516 Palmyra, areas of high coral cover $(>50 \%)$ are generally associated with moderate wave stress,

517 suggestive of this balance between nutrient supply and reduction in breakage, and the importance

518 of wave stress on the benthic community (Figure 14a) (Rogers et al., 2016a).

519 The near bed mean flows are nearly similar for all biological cover types, with some preference

520 for higher flows for the highest coral cover areas (>50\%) (Figure 14b). Therefore, mean flows

521 appear to only be weakly associated with higher coral cover at this site.

522 Offshore travel time (age) is defined as the average time taken for offshore water to come to a 523 particular point on the atoll. This metric likely includes the effect of multiple processes on the

524 reef, notably water quality and temperature. The longer a parcel of water spends in the atoll

525 system, the greater the effects from changes in nutrients, oxygen, alkalinity, $\mathrm{pH}$, compared to

526 offshore waters. At this site, areas with moderate to high coral cover $(>10 \%)$ are generally

527 associated with low water age, while areas with low coral cover $(>10 \%)$ are associated with high

528 water age (Figure 14c). The deep lagoon waters are known to be regularly anoxic and sulphidic,

529 conditions which are detrimental to corals (Gardner et al., 2014a). The longer a parcel spends in

530 the atoll system, the more it is subjected to the local heating effects, as compared to the relatively

531 stable offshore water temperatures. The effect of age on biological cover is likely mostly a

532 function of temperature and to a lesser extent water quality (i.e., nutrients, oxygen, alkalinity,

533 and/or $\mathrm{pH})$.

534 Temperature variations are well-known to influence coral reefs which have experienced global

535 declines resulting from bleaching events caused by week to month long warm water exposure

536 (Carpenter et al., 2008; Hughes et al., 2003). However, corals can often resist high temperature

537 variability at hourly timescales (Dandan et al., 2015; Mayfield et al., 2013), and the spatial

538 variations in coral cover appear to be most correlated to temperature variations on time scales of

539 days to weeks (Rogers et al., 2016b). These model results show areas with high coral cover

$540(>50 \%)$ associated with lower weekly temperatures, while sites with low coral cover $(<10 \%)$ are

541 associated with high weekly temperatures (Figure 14d). These results agree with previous

542 findings from multi-year field observations on Palmyra (Rogers et al., 2016b). 
543 In general, areas of high coral cover $(>50 \%)$ are associated with moderate wave stress, lower 544 age, and lower temperature, while areas of very low coral cover $(<10 \%)$ are associated with high

545 water age and high temperature. Thus, moderate wave stress, low water age, and lower

546 temperatures appear to be part of the suite of conditions necessary for high coral cover at this

547 site. Corals at this site are close to their high thermal limit (Rogers et al., 2016b; Williams et al.,

548 2010), and so temperature has a strong effect on coral zonation. Interestingly, Rogers et al.

549 (2016b) found that the physical factors favoring high coral cover percentage varied according to

550 the different prevailing hydrodynamic regimes: low temperatures in backreef habitats, short

551 travel times in lagoon habitats (days since entering the reef system), and lower wave stress on

552 forereef habitats, a pattern which is likely present here too. Rogers et al. (2016b) also note that

553 light of future warming from climate change, local areas of reefs which maintain lower

554 temperatures through wave-driven mean flows will have the best likelihood of promoting coral

555 survival, a conclusion also supported by these results.

\section{Conclusions}

557 We present results from modeling simulations using a coupled wave and three-dimensional 558 hydrodynamic model (COAWST) applied to Palmyra Atoll. This study is the first time that the 559 vortex force formalism has been implemented in an environment with very high bottom drag. In 560 addition, the model uses a modified bottom friction formulation in the SWAN wave model 561 (Rogers et al., 2016a) to account for the high bottom friction characteristic of this setting and 562 likely many other tropical atolls. Considering the model complexity in terms of bathymetry, 563 bottom roughness, and forcing (waves, wind, metrological, tides, regional boundary conditions), 564 and open boundary conditions from a global model, the results for depth averaged quantities, 565 tides, and vertical structure are in good agreement with the field observations. The model over 566 predicts mixing in the deep lagoons due to spurious vertical velocities, and over predicts 567 exchange in the East Lagoon due to poorly resolved inlets. Outside of these regions, the model 568 results are in good agreement with field observations. Future model development in similar 569 environments should carefully consider the bathymetry in areas of hydrodynamic controls and 570 correct bottom stress parameterization. 
571 At the atoll scale, strong regional flows create flow separation and a well-defined wake, similar

572 to 2D flow past a cylinder, and consistent with previous work on island wakes. Vortices are shed 573 from the leading edge of the wake, which can interact with the atoll and enhance connectivity by

574 redistributing waters across different regions.

575 Momentum balances indicate the important forcing mechanisms, and are strongly a function of 576 depth and hydrodynamic regime. Bottom stress is a significant term in the momentum balance 577 everywhere for depths less than $60 \mathrm{~m}$. Circulation within the atoll is generally driven by waves 578 over the reef crest and from east to west within the interior lagoon system, and this wave-driven 579 flow is modulated by the tides in areas of shallow depth.

580 The Lagrangian connectivity is obtained from the float track model results. The resulting 581 connectivity within the atoll system shows that the general trends follow the mean flow paths, 582 i.e. from west to east on the atoll exterior reefs and from east to west within the interior lagoon 583 system. However, some connectivity exists between all regions of the atoll system, due to tidal 584 phasing, vortices and other nonlinear interactions.

585 Moderate wave stress, short travel time (days since entering the reef system), and low 586 temperature appear to be the most ideal conditions for high coral cover at this site. Corals at this 587 site are close to their high thermal limit (Rogers et al., 2016b; Williams et al., 2010), and so 588 temperature has a strong effect on coral zonation. The effect of travel time on biological cover is 589 likely mostly a function of temperature and to a lesser extent water quality. In light of future 590 warming from climate change, local areas of reefs which maintain lower temperatures through 591 wave-driven mean flows will have the best likelihood of promoting coral survival

592 Future work could examine the effects of density driven flow, which are likely important in some 593 regions of the atoll such as the interior lagoons and outlet channels. Additional work could 594 explicitly model larval connectivity, considering vertical location in the water column and larval 595 swimming patterns. Finally, for this study, extensive field data at multiple sites allowed for 596 calculation of roughness values to parameterize the model. Development of methods for 597 selection of roughness values a priori from high resolution bathymetric data or other site 598 mapping would warrant further inquiry. 


\section{Acknowledgements}

600 We thank Matthew Rayson, Sean Vitousek, and John Warner for assistance with modeling.

601 Bathymetry and other information were provided by Jamison Gove. Research funding was

602 provided by Stanford University along with two grants from the Gordon and Betty Moore

603 Foundation ("Observations and modeling of the C system dynamics at Palmyra Atoll: In support

604 of the development of management strategies for ocean acidification impacts in the tropics," to

605 RBD and, "Understanding coral reef resilience to advance science and conservation," to RBD

606 and SGM), as well as a grant from the National Science Foundation OCE-1536502

607 (“Collaborative Research: Wave driven flow through a shallow, fringing reef” to SGM). This

608 research was accomplished with government support under and awarded by the U.S. Department 609 of Defense, Office of Naval Research, NDSEG Fellowship, 32 CFR 168a to JSR. DAK was

610 funded by an NSF Graduate Research Fellowship. This is Palmyra Atoll Research Consortium

611 contribution number PARC-0127.

612 List of References

613

614

615

616

617

618

619

620

621

622

623

624

625

626

627

628

629

630

631

632

633
Acevedo, R., Morelock, J., Olivieri, R., 1989. Modification of coral reef zonation by terrigenous sediment stress. Palaios 4, 92-100.

Andréfouët, S., Ardhuin, F., Queffeulou, P., Le Gendre, R., 2012. Island shadow effects and the wave climate of the Western Tuamotu Archipelago (French Polynesia) inferred from altimetry and numerical model data. Mar. Pollut. Bull. 65, 415-24. doi:10.1016/j.marpolbul.2012.05.042

Andréfouët, S., Mumby, P., McField, M., Hu, C., Muller-Karger, F., 2002. Revisiting coral reef connectivity. Coral Reefs 21, 43-48. doi:10.1007/s00338-001-0199-0

Andréfouët, S., Ouillon, S., Brinkman, R., Falter, J., Douillet, P., Wolk, F., Smith, R., Garen, P., Martinez, E., Laurent, V., Lo, C., Remoissenet, G., Scourzic, B., Gilbert, a, Deleersnijder, E., Steinberg, C., Choukroun, S., Buestel, D., 2006. Review of solutions for 3D hydrodynamic modeling applied to aquaculture in South Pacific atoll lagoons. Mar. Pollut. Bull. 52, 1138-55. doi:10.1016/j.marpolbul.2006.07.014

Arístegui, J., Sangrá, P., Hernández-León, S., Cantón, M., Hernández-Guerra, A., Kerling, J.L., 1994. Island-induced eddies in the Canary islands. Deep Sea Res. Part I Oceanogr. Res. Pap. 41, 1509-1525. doi:10.1016/0967-0637(94)90058-2

Atkinson, M.J., Bilger, R.W., 1992. Effects of water velocity on phosphate uptake in coral reefflat communities. Limnol. Ocean. 37, 273-279. doi:10.4319/lo.1992.37.2.0273

Atkinson, M.J., Smith, S. V., Stroup, E.D., 1981. Circulation in Enewetak Atoll lagoon. Limnol. Oceanogr. 26, 1074-1083. doi:10.4319/lo.1981.26.6.1074

Booij, N., Ris, R.C., Holthuijsen, L.H., 1999. A third-generation wave model for coastal regions:

Rogers et al.

Oct 2016, Rev 2 
1. Model description and validation. J. Geophys. Res. 104, 7649-7666. doi:10.1029/98JC02622

Buddemeier, R.W., Hopley, D., 1988. Turn-ons and turn-offs: Causes and mechanisms of the initiation and termination of coral reef growth, in: International Coral Reef Symposium. Townsville, Australia.

Burke, L., Reytar, K., Spalding, M., Perry, A., 2011. Reefs at risk revisited. World Resources Institute, Washington DC.

Callaghan, D.P., Nielsen, P., Cartwright, N., Gourlay, M.R., Baldock, T.E., 2006. Atoll lagoon flushing forced by waves. Coast. Eng. 53, 691-704. doi:10.1016/j.coastaleng.2006.02.006

Carpenter, K.E., Abrar, M., Aeby, G., Aronson, R.B., Banks, S., Bruckner, A., Chiriboga, A., Cortés, J., Delbeek, J.C., Devantier, L., Edgar, G.J., Edwards, A.J., Fenner, D., Guzmán, H.M., Hoeksema, B.W., Hodgson, G., Johan, O., Licuanan, W.Y., Livingstone, S.R., Lovell, E.R., Moore, J.A., Obura, D.O., Ochavillo, D., Polidoro, B.A., Precht, W.F., Quibilan, M.C., Reboton, C., Richards, Z.T., Rogers, A.D., Sanciangco, J., Sheppard, A., Sheppard, C., Smith, J., Stuart, S., Turak, E., Veron, J.E.N., Wallace, C., Weil, E., Wood, E., 2008. One-third of reef-building corals face elevated extinction risk from climate change and local impacts. Science (80-. ). 321, 560-563. doi:10.1126/science. 1159196

Carpenter, R.C., Hackney, J.M., Adey, W.H., 1991. Measurements of primary productivity and nitrogenase activity of coral reef algae in a chamber incorporating oscillatory flow. Limnol. Oceanogr. 36, 40-49. doi:10.4319/lo.1991.36.1.0040

Chappell, J., 1980. Coral morphology, diversity and reef growth. Nature 286, 249-252. doi: $10.1038 / 286249 \mathrm{a} 0$

Cowen, R.K., Sponaugle, S., 2009. Larval Dispersal and Marine Population Connectivity. Ann. Rev. Mar. Sci. 1, 443-466. doi:10.1146/annurev.marine.010908.163757

Craik, A.D.D., Leibovich, S., 1976. A rational model for Langmuir circulations. J. Fluid Mech. 73, 401. doi:10.1017/S0022112076001420

Dandan, S.S., Falter, J.L., Lowe, R.J., McCulloch, M.T., 2015. Resilience of coral calcification to extreme temperature variations in the Kimberley region, northwest Australia. Coral Reefs 34, 1151-1163. doi:10.1007/s00338-015-1335-6

Darwin, C.H., 1842. The Structure and Distribution of Coral Reefs. Smith, Elder and Co., London.

Delesalle, B., Sournia, A., 1992. Residence time of water and phytoplankton biomass in coral reef lagoons. Cont. Shelf Res. 12, 939-949. doi:10.1016/0278-4343(92)90053-M

Douillet, P., Ouillon, S., Cordier, E., 2001. A numerical model for fine suspended sediment transport in the southwest lagoon of New Caledonia. Coral Reefs 20, 361-372. doi:10.1007/s00338-001-0193-6

Dumas, F., Le Gendre, R., Thomas, Y., Andréfouët, S., 2012. Tidal flushing and wind driven circulation of Ahe atoll lagoon (Tuamotu Archipelago, French Polynesia) from in situ observations and numerical modelling. Mar. Pollut. Bull. 65, 425-440. doi:10.1016/j.marpolbul.2012.05.041

Egbert, G.D., Erofeeva, S.Y., 2002. Efficient Inverse Modeling of Barotropic Ocean Tides. J. Atmos. Ocean. Technol. 19, 183-204. doi:10.1175/15200426(2002)019<0183:EIMOBO>2.0.CO;2

Fabricius, K.E., 2005. Effects of terrestrial runoff on the ecology of corals and coral reefs: Review and synthesis. Mar. Pollut. Bull. 50, 125-146. doi:10.1016/j.marpolbul.2004.11.028 Fringer, O.B., Gerritsen, M., Street, R.L., 2006. An unstructured-grid, finite-volume, 
nonhydrostatic, parallel coastal ocean simulator. Ocean Model. 14, 139-173. doi:10.1016/j.ocemod.2006.03.006

Gardner, J.P.A., Garton, D.W., Collen, J.D., Zwartz, D., 2014a. Distant storms as drivers of environmental change at Pacific atolls. PLoS One 9, e87971. doi:10.1371/journal.pone.0087971

Gardner, J.P.A., John Bartz, R., Brainard, R.E., Collen, J.D., Dunbar, R.B., Garton, D.W., Powell, S., 2014b. Conservation management options and actions: Putative decline of coral cover at Palmyra Atoll, Northern Line Islands, as a case study. Mar. Pollut. Bull. 84, 182190. doi:10.1016/j.marpolbul.2014.05.013

Genin, A., Monismith, S.G., Reidenbach, M.A., Yahel, G., Koseff, J.R., 2009. Intense benthic grazing of phytoplankton in a coral reef. Limnol. Oceanogr. 54, 938-951. doi:10.4319/lo.2009.54.3.0938

Haidvogel, D.B., Arango, H., Budgell, W.P., Cornuelle, B.D., Curchitser, E., Di Lorenzo, E., Fennel, K., Geyer, W.R., Hermann, A.J., Lanerolle, L., Levin, J., McWilliams, J.C., Miller, A.J., Moore, A.M., Powell, T.M., Shchepetkin, A.F., Sherwood, C.R., Signell, R.P., Warner, J.C., Wilkin, J., 2008. Ocean forecasting in terrain-following coordinates: Formulation and skill assessment of the Regional Ocean Modeling System. J. Comput. Phys. 227, 3595-3624. doi:10.1016/j.jcp.2007.06.016

Hench, J., Leichter, J.J., Monismith, S.G., 2008. Episodic circulation and exchange in a wave-driven coral reef and lagoon system. Limnol. Oceanogr. 53, 2681-2694.

Hoegh-Guldberg, O., Mumby, P.J.P.J., Hooten, A.J.J., Stenack, R.S., Greenfield, P., Gomez, E., Harvell, C.D.D., Sale, P.F., Edwards, A.J., Caldeira, K., Knowlton, N., Eakin, C.M., Inglesias-Priesto, R., Muthiga, N., Bradbury, R.H., Dubi, A., Hatziolos, M.E.E., Steneck, R.S., Greenfield, P., Gomez, E., Harvell, C.D.D., Sale, P.F., Edwards, A.J., Caldeira, K., Knowlton, N., Eakin, C.M., Iglesias-Prieto, R., Muthiga, N., Bradbury, R.H., Dubi, A., Hatziolos, M.E.E., 2007. Coral Reefs Under Rapid Climate Change and Ocean Acidification. Science (80-. ). 318, 1737-1742. doi:10.1126/science.1152509

Hoeke, R.K., Storlazzi, C.D., Ridd, P. V., 2013. Drivers of circulation in a fringing coral reef embayment: A wave-flow coupled numerical modeling study of Hanalei Bay, Hawaii. Cont. Shelf Res. 58, 79-95. doi:10.1016/j.csr.2013.03.007

Hsin, Y.-C.C., Qiu, B., 2012. Seasonal fluctuations of the surface North Equatorial Countercurrent (NECC) across the Pacific basin. J. Geophys. Res. Ocean. 117, 1-17. doi:10.1029/2011JC007794

Hughes, T.P., Baird, A.H., Bellwood, D.R., Card, M., Connolly, S.R., Folke, C., Grosberg, R., Hoegh-Guldberg, O., Jackson, J.B.C., Kleypas, J., Lough, J.M., Marshall, P., Nyström, M., Palumbi, S.R., Pandolfi, J.M., Rosen, B., Roughgarden, J., 2003. Climate Change , Human Impacts, and the Resilience of Coral Reefs. Science (80-. ). 301, 929-933. doi: $10.1126 /$ science. 1085046

Jones, G.P., Almany, G.R., Russ, G.R., Sale, P.F., Steneck, R.S., van Oppen, M.J.H., Willis, B.L., 2009. Larval retention and connectivity among populations of corals and reef fishes: history, advances and challenges. Coral Reefs 28, 307-325. doi:10.1007/s00338-009-04699

Kench, P.S., 1998. Physical processes in a semi-enclosed Indian Ocean. Coral Reefs 17, 13. Kleypas, J.A., 1999. Geochemical Consequences of Increased Atmospheric Carbon Dioxide on Coral Reefs. Science (80-. ). 284, 118-120. doi:10.1126/science.284.5411.118

Koweek, D.A., Dunbar, R.B., Monismith, S.G., Mucciarone, D.A., Woodson, C.B., Samuel, L.,

Rogers et al. 
2015a. High-resolution physical and biogeochemical variability from a shallow back reef on Ofu, American Samoa: an end-member perspective. Coral Reefs. doi:10.1007/s00338-0151308-9

Koweek, D.A., Dunbar, R.B., Rogers, J.S., Williams, G.J., Price, N., Mucciarone, D.A., Teneva, L., 2015b. Environmental and ecological controls of coral community metabolism on Palmyra Atoll. Coral Reefs 34, 339-351. doi:10.1007/s00338-014-1217-3

Kraines, S., Yanagi, T., Isobe, M., Komiyama, H., 1998. Wind-wave driven circulation on the coral reef at Bora Bay, Miyako Island. Coral Reefs 17, 133-143. doi: $10.1007 / \mathrm{s} 003380050107$

Kumar, N., Feddersen, F., Uchiyama, Y., McWilliams, J.C., O’Reilly, W., 2015. Midshelf to Surfzone Coupled ROMS-SWAN Model Data Comparison of Waves, Currents, and Temperature: Diagnosis of Subtidal Forcings and Response. J. Phys. Oceanogr. 45, 14641490. doi:10.1175/JPO-D-14-0151.1

Kumar, N., Voulgaris, G., Warner, J.C., Olabarrieta, M., 2012. Implementation of the vortex force formalism in the coupled ocean-atmosphere-wave-sediment transport (COAWST) modeling system for inner shelf and surf zone applications. Ocean Model. 47, 65-95. doi:10.1016/j.ocemod.2012.01.003

Kumar, N., Voulgaris, G., Warner, J.C.C., 2011. Implementation and modification of a threedimensional radiation stress formulation for surf zone and rip-current applications. Coast. Eng. 58, 1097-1117. doi:10.1016/j.coastaleng.2011.06.009

Lentz, S.J., Churchill, J.H., Davis, K.A., Farrar, J.T., Pineda, J., Starczak, V., 2016. The characteristics and dynamics of wave-driven flow across a platform coral reef in the Red Sea. J. Geophys. Res. Ocean. doi:10.1002/2015JC011141

Longuet-Higgins, M.S., Stewart, R. w., 1964. Radiation stresses in water waves; a physical discussion, with applications. Deep Sea Res. Oceanogr. Abstr. 11, 529-562. doi:10.1016/0011-7471(64)90001-4

Lowe, R.J., Falter, J.L., 2015. Oceanic Forcing of Coral Reefs. Ann. Rev. Mar. Sci. 7, 43-66. doi:10.1146/annurev-marine-010814-015834

Lowe, R.J., Falter, J.L., Monismith, S.G., Atkinson, M.J., 2009a. A numerical study of circulation in a coastal reef-lagoon system. J. Geophys. Res. Ocean. 114, 1-18. doi:10.1029/2008JC005081

Lowe, R.J., Falter, J.L., Monismith, S.G., Atkinson, M.J., 2009b. Wave-Driven Circulation of a Coastal Reef - Lagoon System. J. Phys. Oceanogr. 39, 873-893. doi:10.1175/2008JPO3958.1

Lugo-Fernández, A., Roberts, H.H., Wiseman, W.J., 2004. Currents, water levels, and mass transport over a modern Caribbean coral reef: Tague Reef, St. Croix, USVI. Cont. Shelf Res. 24, 1989-2009. doi:10.1016/j.csr.2004.07.004

Maragos, J.E., Friedlander, A.M., Godwin, S., Musburger, C., Tsuda, R., Flint, E., Pantos, O., Ayotte, P., Sala, E., Sandin, S., McTee, S., Siciliano, D., Obura, D., 2008. US coral reefs in the Line and Phoenix Islands, central Pacific Ocean: status, threats and significance. Coral Reefs USA 643-654.

Mayfield, A.B., Chen, M.N., Meng, P.J., Lin, H.J., Chen, C.S., Liu, P.J., 2013. The physiological response of the reef coral Pocillopora damicornis to elevated temperature: Results from coral reef mesocosm experiments in Southern Taiwan. Mar. Environ. Res. 86, 1-11. doi:10.1016/j.marenvres.2013.01.004

Mellor, G., 2011. Wave radiation stress. Ocean Dyn. 61, 563-568. doi:10.1007/s10236-010- 
0359-2

Mellor, G.L., 2008. The Depth-Dependent Current and Wave Interaction Equations: A Revision. J. Phys. Oceanogr. 38, 2587-2596. doi:10.1175/2008JPO3971.1

Monismith, S.G., 2007. Hydrodynamics of Coral Reefs. Annu. Rev. Fluid Mech. 39, 37-55. doi:10.1146/annurev.fluid.38.050304.092125

Monismith, S.G., Genin, A., Reidenbach, M. a., Yahel, G., Koseff, J.R., 2006. Thermally Driven Exchanges between a Coral Reef and the Adjoining Ocean. J. Phys. Oceanogr. 36, 13321347. doi:10.1175/JPO2916.1

Monismith, S.G., Herdman, L.M.M., Ahmerkamp, S., Hench, J.L., 2013. Wave transformation and wave-driven flow across a steep coral reef. J. Phys. Oceanogr. 43, 1356-1379. doi:10.1175/JPO-D-12-0164.1

Monismith, S.G., Rogers, J.S., Koweek, D.A., Dunbar, R.B., 2015. Frictional wave dissipation on a remarkably rough reef. Geophys. Res. Lett. 42, 1-9. doi:10.1002/2015GL063804

Monsen, N.E., Cloern, J.E., Lucas, L. V., Monismith, S.G., 2002. The use of flushing time, residence time, and age as transport time scales. Limnol. Oceanogr. 47, 1545-1553. doi:10.4319/lo.2002.47.5.1545

Munk, W.H., Sargent, M.C., 1954. Adjustment of Bikini Atoll to ocean waves, U. S. Geol. Sur. Prof. Paper 260-C.

Odum, H.T., Odum, E.P., 1955. Trophic Structure and Productivity of a Windward Coral Reef Community on Eniwetok Atoll. Ecol. Monogr. 25, 291-320.

Palumbi, S.R., Barshis, D.J., Traylor-Knowles, N., Bay, R.A., 2014. Mechanisms of reef coral resistance to future climate change. Science (80-. ). 344, 895-898.

Riegl, B., Dodge, R., 2008. Coral Reefs of the USA. Elsevier. doi:10.1007/978-1-4020-6847-8

Roberts, C.M., 1997. Connectivity and management of Caribbean coral reefs. Science (80-. ). 278, 1454-1457. doi:10.1126/science.278.5342.1454

Rogers, C.S.C., 1990. Responses of coral reefs and reef organisms to sedimentation. Mar. Ecol. Prog. Ser. 62, 185-202. doi:10.3354/meps062185

Rogers, J.S., 2015. Physical oceanography in coral reef environments wave and mean flow dynamics at small and large scales, and resulting ecological implications. Stanford University.

Rogers, J.S., Monismith, S.G., Dunbar, R.B., Koweek, D.A., 2015. Field observations of wavedriven circulation over spur and groove formations on a coral reef. J. Geophys. Res. 120, 145-160. doi:10.1002/2014JC010464

Rogers, J.S., Monismith, S.G., Koweek, D.A., Dunbar, R.B., 2016a. Wave dynamics of a Pacific Atoll with high frictional effects. J. Geophys. Res. 121, 350-367. doi:10.1002/2015JC011170

Rogers, J.S., Monismith, S.G., Koweek, D.A., Torres, W.I., Dunbar, R.B., 2016b. Thermodynamics and hydrodynamics in an atoll reef system and their influence on coral cover. Limnol. Oceanogr. doi:10.1002/lno.10365

Rosman, J.H., Hench, J.L., 2011. A framework for understanding drag parameterizations for coral reefs. J. Geophys. Res. Ocean. 116, 1-15. doi:10.1029/2010JC006892

Sandin, S.A., Smith, J.E., Demartini, E.E., Dinsdale, E.A., Donner, S.D., Friedlander, A.M., Konotchick, T., Malay, M., Maragos, J.E., Obura, D., Pantos, O., Paulay, G., Richie, M., Rohwer, F., Schroeder, R.E., Walsh, S., Jackson, J.B.C., Knowlton, N., Sala, E., 2008. Baselines and Degradation of Coral Reefs in the Northern Line Islands. PLoS One 3, e1548. doi:10.1371/journal.pone.0001548 
Shchepetkin, A.F., McWilliams, J.C., 2009. Correction and commentary for "Ocean forecasting in terrain-following coordinates: Formulation and skill assessment of the regional ocean modeling system" by Haidvogel et al., J. Comp. Phys. 227, pp. 3595-3624. J. Comput. Phys. 228, 8985-9000. doi:10.1016/j.jcp.2009.09.002

Shchepetkin, A.F., McWilliams, J.C., 2005. The regional oceanic modeling system (ROMS): A split-explicit, free-surface, topography-following-coordinate oceanic model. Ocean Model. 9, 347-404. doi:10.1016/j.ocemod.2004.08.002

Shchepetkin, A.F., McWilliams, J.C., 2003. A method for computing horizontal pressuregradient force in an oceanic model with a nonaligned vertical coordinate. J. Geophys. Res. 108, 3090--. doi:10.1029/2001JC001047

Stevenson, C., Katz, L.S., Micheli, F., Block, B., Heiman, K.W., Perle, C., Weng, K., Dunbar, R.B., Witting, J., 2007. High apex predator biomass on remote Pacific islands. Coral Reefs 26, 47-51. doi:10.1007/s00338-006-0158-x

Stevenson, S., Powell, B.S., Merrifield, M.A., Cobb, K.M., Nusbaumer, J., Noone, D., 2015. Characterizing seawater oxygen isotopic variability in a regional ocean modeling framework: Implications for coral proxy records. Paleoceanography 30, 1573-1593. doi:10.1002/2015PA002824

Storlazzi, C.D., Brown, E.K., Field, M.E., Rodgers, K., Jokiel, P.L., 2005. A model for wave control on coral breakage and species distribution in the Hawaiian Islands. Coral Reefs 24, 43-55. doi:10.1007/s00338-004-0430-x

Symonds, G., Black, K.P., Young, I.R., 1995. Wave-driven flow over shallow reefs. J. Geophys. Res. 100, 2639. doi:10.1029/94JC02736

Uchiyama, Y., McWilliams, J.C., Shchepetkin, A.F., 2010. Wave-current interaction in an oceanic circulation model with a vortex-force formalism: Application to the surf zone. Ocean Model. 34, 16-35. doi:10.1016/j.ocemod.2010.04.002

Warner, J.C., Armstrong, B., He, R., Zambon, J.B., 2010. Development of a Coupled OceanAtmosphere-Wave-Sediment Transport (COAWST) Modeling System. Ocean Model. 35, 230-244. doi:10.1016/j.ocemod.2010.07.010

Warner, J.C., Sherwood, C.R., Arango, H.G., Signell, R.P., 2005. Performance of four turbulence closure models implemented using a generic length scale method. Ocean Model. 8, 81-113. doi:10.1016/j.ocemod.2003.12.003

Williams, G.J., Knapp, I.S., Maragos, J.E., Davy, S.K., 2010. Modeling patterns of coral bleaching at a remote Central Pacific atoll. Mar. Pollut. Bull. 60, 1467-1476. doi:10.1016/j.marpolbul.2010.05.009

Williams, G.J., Smith, J.E., Conklin, E.J., Gove, J.M., Sala, E., Sandin, S.A., 2013. Benthic communities at two remote Pacific coral reefs: effects of reef habitat, depth, and wave energy gradients on spatial patterns. PeerJ 1, e81. doi:10.7717/peerj.81

Willmott, C., 1982. Some comments on the evaluation of model performance. Bull. Am. Meteorol. Soc. doi:10.1175/1520-0477(1982)063<1309:SCOTEO>2.0.CO;2

Wolanski, E., Asaeda, T., Tanaka, A., Deleersnijder, E., 1996. Three-dimensional island wakes in the field, laboratory experiments and numerical models. Cont. Shelf Res. 16, 1437-1452.

Yahel, G., Post, A.F., Fabricius, K., Marie, D., Vaulot, D., Genin, A., 1998. Phytoplankton distribution and grazing near coral reefs. Limnol. Oceanogr. 43, 551-563.

Young, I.R., 1989. Wave transformation over coral reefs. J. Geophys. Res. 94, 9779. doi:10.1029/JC094iC07p09779 


\section{$864 \quad$ Figure Legends}

865 Figure 1. Palmyra Atoll location, site layout and experiment instrumentation (a) location of

866

867

868

869

870

871

872

873

874

875

876

877

878

879

880

881

882

883

884

885

886

887

888

889

890

891

892

893

894

895

896

897

898

899

900

901

902
Palmyra Atoll, (b) layout of atoll and instrument locations for long term measurement $[(U, \zeta, T)$ magenta squares; $(\zeta, T)$ magenta circles; $(T)$ small magenta circles), and weather station (green star), image courtesy of NOAA. (c) typical southern forereef with abundant live coral and green sea turtle (Chelonia mydas), (d) typical rugose reef on shallow terrace with live coral and fish, and (e) percent coral cover mapping courtesy of NOAA. Gray line on (b, e) is $100 \mathrm{~m}$ depth contour, (c, d) courtesy of Brian Zgliczynski.

Figure 2. Oceanographic setting and model forcing parameters from 2012 to 2014 during model run times for Runs 1 to 4 . Forcing from (a) significant wave height $H_{s}$ offshore of the northern and southern sides of the atoll, (b) free surface height $\zeta$, (c) wind $U_{10}$ (direction wind is going), (d) regional currents $U_{\text {reg }}$ (avg. of upper $50 \mathrm{~m}$ of HYCOM) and (f) temperature $T$ (avg. of all field records). Low pass filtering $\left(l_{p}\right)$ is on a weekly average. Gray bars show extent of model runs.

Figure 3. Model grid layout, bathymetry and bottom roughness. (a) Model grid extent (red outline) and bathymetry, with HYCOM boundary condition grid (gray --), (b) depth grid detail $h$ (m) zoomed to atoll with location of selected instrument stations, and (c) bottom roughness grid $z_{0}(\mathrm{~m})$. Gray lines are $(2,10,30,60,200 \mathrm{~m})$ depth contours for (b), and $60 \mathrm{~m}$ for (c); gray shading is land mask.

Figure 4. Selected model validation data for three sites (FR7, RT4, and CHAN) for Run 1 (Nov2012) for (a-c) mean surface height $\zeta$, (d-f) depth averaged alongshore velocity $U_{A S}$, (g-i) depth averaged cross-shore velocity $U_{C S}$, and (j-1) near-bottom temperature $T_{b}$. Black is field observation, red is model result, for (d-1), light colors are instantaneous values and dark colors are subtidal filtered $(36 \mathrm{hr})$. Time is since start of model run; three days of model spinup not shown.

Figure 5. Comparison of observed and modeled M2 tides. (a) tidal amplitude and (b) tidal phase for observations (black) and model (red) for Run 1 (Nov 2012), with progression into atoll interior at three sites (FR3, CHAN, EL).

Figure 6. Comparison of vertical profiles of velocity (top) and temperature (bottom) for observations (black) and model results (red) at four sites for Run 1 (Nov 2012). (a-d) root mean square (rms) velocity $\bar{u}_{r m s}$ in alongshore (-) and cross-shore (--) directions, and (e-h) average temperature $\bar{T}$ profiles. Time averages exclude three days of model spin up. No field measurements available for (d).

Figure 7. Regional flow interaction with the atoll, for 24 hour sequence starting 06-Nov-2012 (left) and 29-Sep-2013 (right). Black arrows are surface velocity $u_{s}$, coloring is surface vorticity $\omega\left(10^{-4} 1 / \mathrm{s}\right)$, gray shading is atoll with black lines as 5 and $60 \mathrm{~m}$ bathymetric contours. Results only shown for depths greater than $10 \mathrm{~m}$.

Figure 8. Relative fraction of contribution from significant 2D momentum terms. (a) acceleration (ACC), (b) horizontal advection (HA), (c) Coriolis (COR), (d) pressure gradient (PG), (e) horizontal vortex force (HVF), (f) bottom stress (Bstr), (g) surface stress (Sstr), and (h)

Rogers et al.

Oct 2016, Rev 2 
903

904

905

906

907

908

909

910

911

912

913

914

915

916

917

918

919

920

921

922

923

924

925

926

927

928

929

930

931

932

933

934

935

936

937

938

939

940

941

wave roller acceleration (RA). Values are average fraction of total momentum budget during Run 1 (Nov 2012), i.e. for term $\bar{X}_{l}=\overline{\left|X_{l}\right| / \sum_{l}\left|X_{l}\right|}$, note log scale. Gray lines are 5 and $60 \mathrm{~m}$ depth contours; gray shading is land mask.

Figure 9. Atoll scale model results snapshot for time period of nighttime dominant northern waves (left) and daytime dominant southern waves (right). (a,b) significant wave height $H_{s}$, (c,d) free surface height $\zeta$, (e,f) surface velocity $u_{s}$, and (g,h) surface temperature $T_{s}$. Gray lines are 5 and $60 \mathrm{~m}$ depth contours; gray shading is land mask. Note offset in scales for (c-d) and (g-h) is different to account for tidal height and regional temperature respectively.

Figure 10. Tidal modulation of wave-driven flow on northeast corner of atoll during Run 1 (Nov 2012). (a) At high tide, waves drive depth averaged velocity $U$ over the reef crest with significant wave height $H_{s}$, while (b) 6 hours previously at low tide and similar $H_{s}$, the reef crest is exposed and waves drive flow alongshore on the forereef. (c) Variation of net flow over the reef crest $q_{\text {crest }}$, with offshore wave energy flux $\mathcal{F}_{\text {wave }}$, and tidal height $\zeta$; line is best fit to the data for $q_{\text {crest }}=a \mathcal{F}_{\text {wave }}^{1 / 5}+b$. For $(\mathrm{a}, \mathrm{b})$, black arrows show direction of $U$, gray shading is land mask, gray lines are 5 and $60 \mathrm{~m}$ depth contours, and magenta lines are $0.3 \mathrm{~m}$ depth contours outlining the reef crest. Location of NB instrument station shown on Figure $3 b$ for reference.

Figure 11. Model results average bottom wave stress, velocity, age and high temperature. (a)

(a) near bottom wave stress proxy $\overline{u_{b w}^{2}}$, (b) average depth averaged velocity $\bar{U}$ (arrows) and near bottom velocity magnitude $\overline{\left|u_{b}\right|}$ (colors), (c) mean offshore travel time (age), and (d) average of $90^{\text {th }}$ percentile weekly average near bottom temperature $\bar{T}_{b 90}$. Averages taken over all model runs. Gray lines are 5 and $60 \mathrm{~m}$ depth contours; gray shading is land mask.

Figure 12. Selected Lagrangian float tracks for Run 1 (Nov 2012), grouped by starting zone (magenta). Colors are time from float initialization on day 2 (blue), to end of run on day 14 (yellow). Only 20 floats per zone are shown for clarity. Gray lines are 5 and $60 \mathrm{~m}$ depth contours; gray shading is land.

Figure 13. Connectivity between hydrodynamic zones. (a) connectivity matrix showing the probability a water parcel passing through a destination zone came from a given source zone, and (b) geographic connectivity of top $10 \%$ of pathways, where shading is relative importance as an overall source, width of line is relative strength of connection. Results based on average of all model runs; gray shading is land mask, gray lines are 5 and $60 \mathrm{~m}$ contours.

Figure 14. Cumulative probability of biological cover as a function of average near bottom wave stress, near bottom velocity, water age, and high weekly temperature. Biological cover with (a) near bottom wave stress proxy $\overline{u_{b w}^{2}}$, (b) average near bottom velocity $\overline{\left|u_{b}\right|}$, (c) offshore travel time (age), and (d) $90^{\text {th }}$ percentile of weekly average near bottom temperature $\bar{T}_{b 90}$. Results are average over all model runs.

Rogers et al.

Oct 2016, Rev 2 


\section{Tables}

946 Table 1. Model skill compared to site observations for free surface height $\zeta$, significant wave height $H_{S}$, 947 alongshore and cross-shore depth averaged velocity $\left(U_{A S}, U_{C S}\right)$, and near bottom temperature $T_{b}$, during 948 Run 1 (Nov 2012).

\begin{tabular}{cccc} 
Variable & Field Sites & Avg. Skill & Std. Skill \\
\hline$\zeta$ & 12 & 0.98 & 0.02 \\
$H_{S}$ & 4 & 0.87 & 0.15 \\
$\overline{U_{A S}}$ & 7 & 0.32 & 0.15 \\
$\overline{U_{C S}}$ & 7 & 0.39 & 0.16 \\
$U_{A S}^{\prime}$ & 7 & 0.42 & 0.16 \\
$U_{C S}^{\prime}$ & 7 & 0.49 & 0.20 \\
$\bar{T}_{b}$ & 23 & 0.73 & 0.17 \\
$T_{b}^{\prime}$ & 23 & 0.58 & 0.20 \\
\hline
\end{tabular}

949 Note: skill excludes initial 3 days for model spin up, $\left(^{-}\right)$is 36 hour low pass filter, $\left(^{\prime}{ }^{\prime}\right)$ is high pass, i.e. $950 \quad T_{b}=\overline{T_{b}}+T_{b}^{\prime}$

951

952

953 

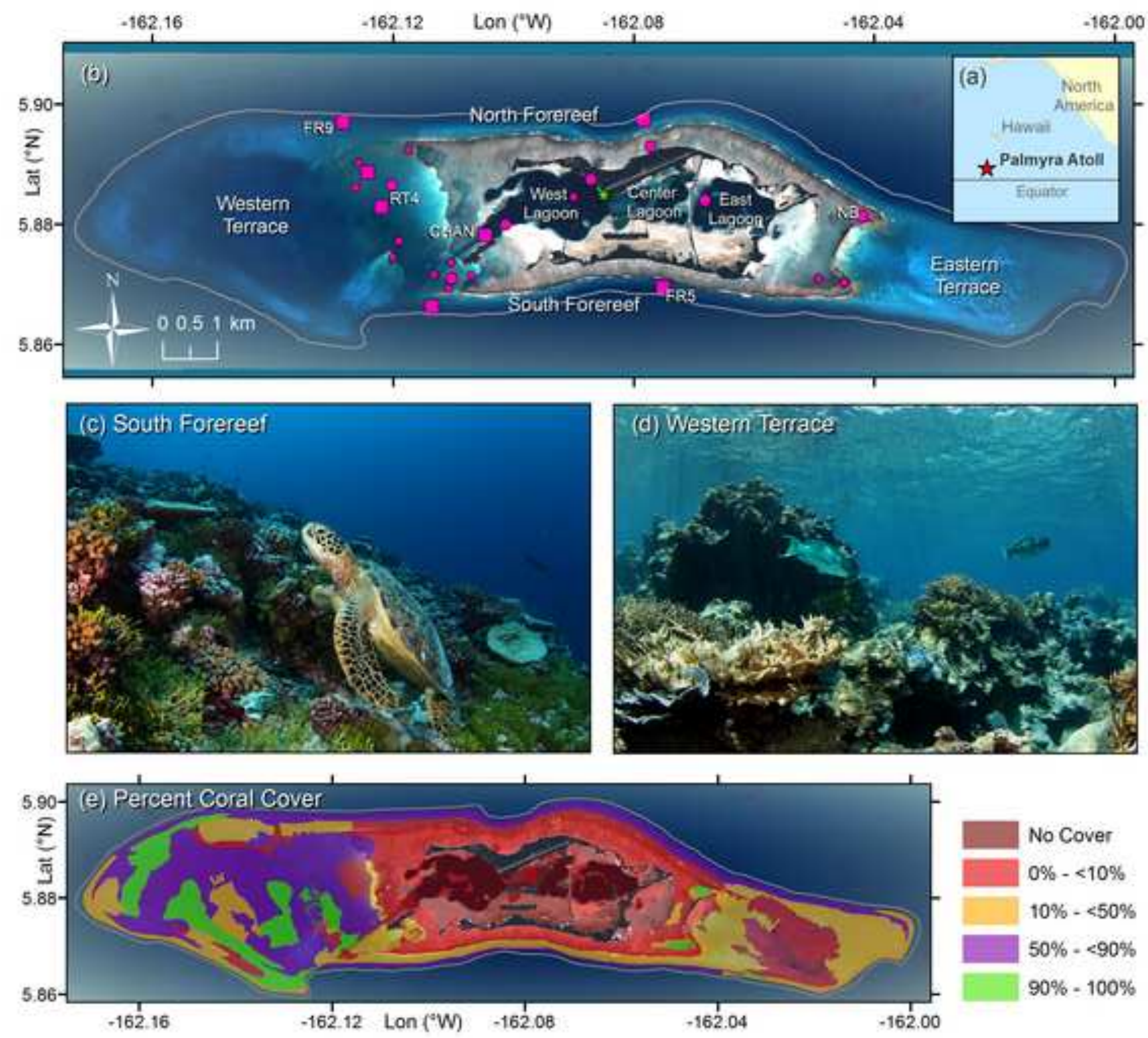


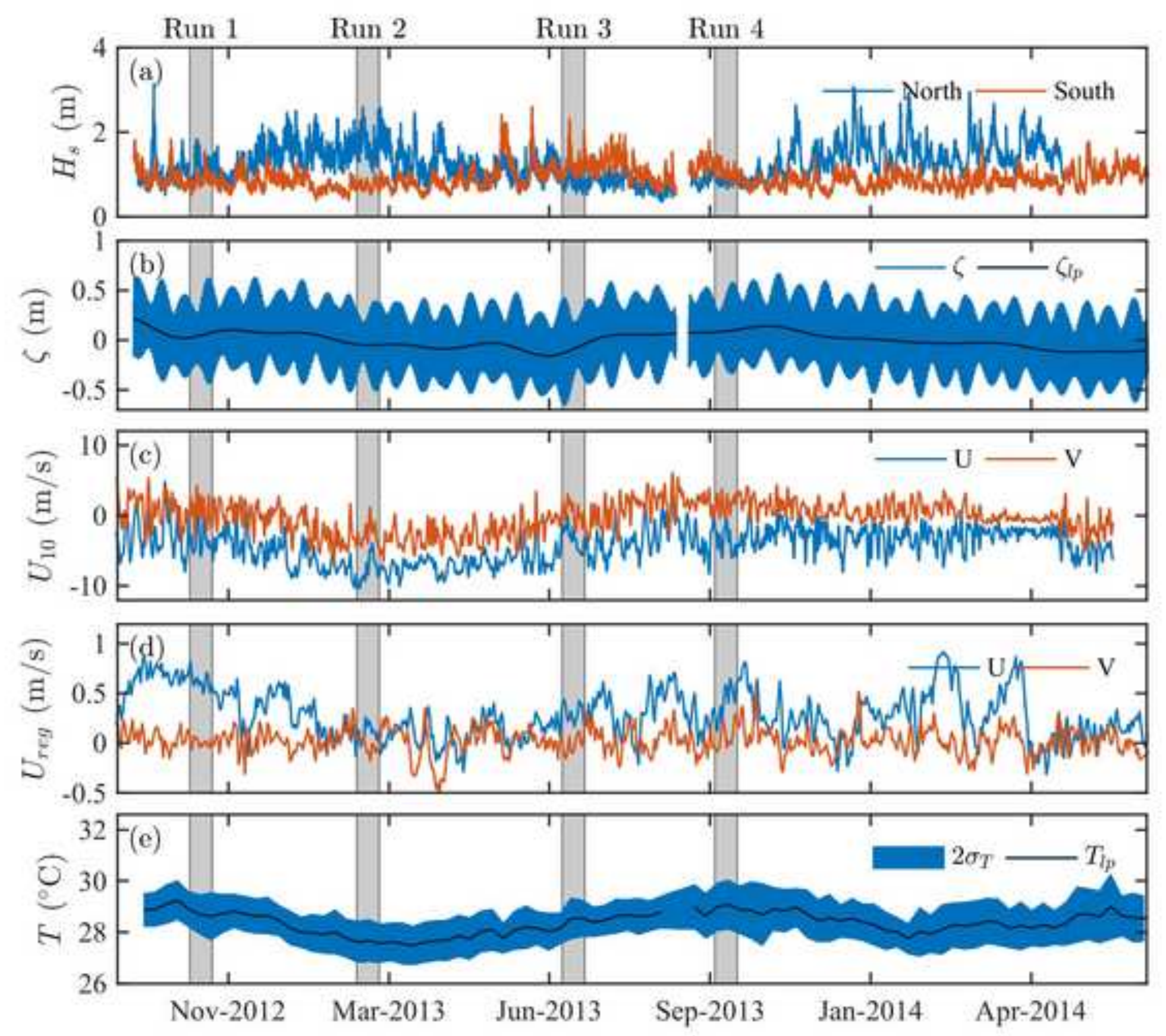


(a) $h(\mathrm{~m})$
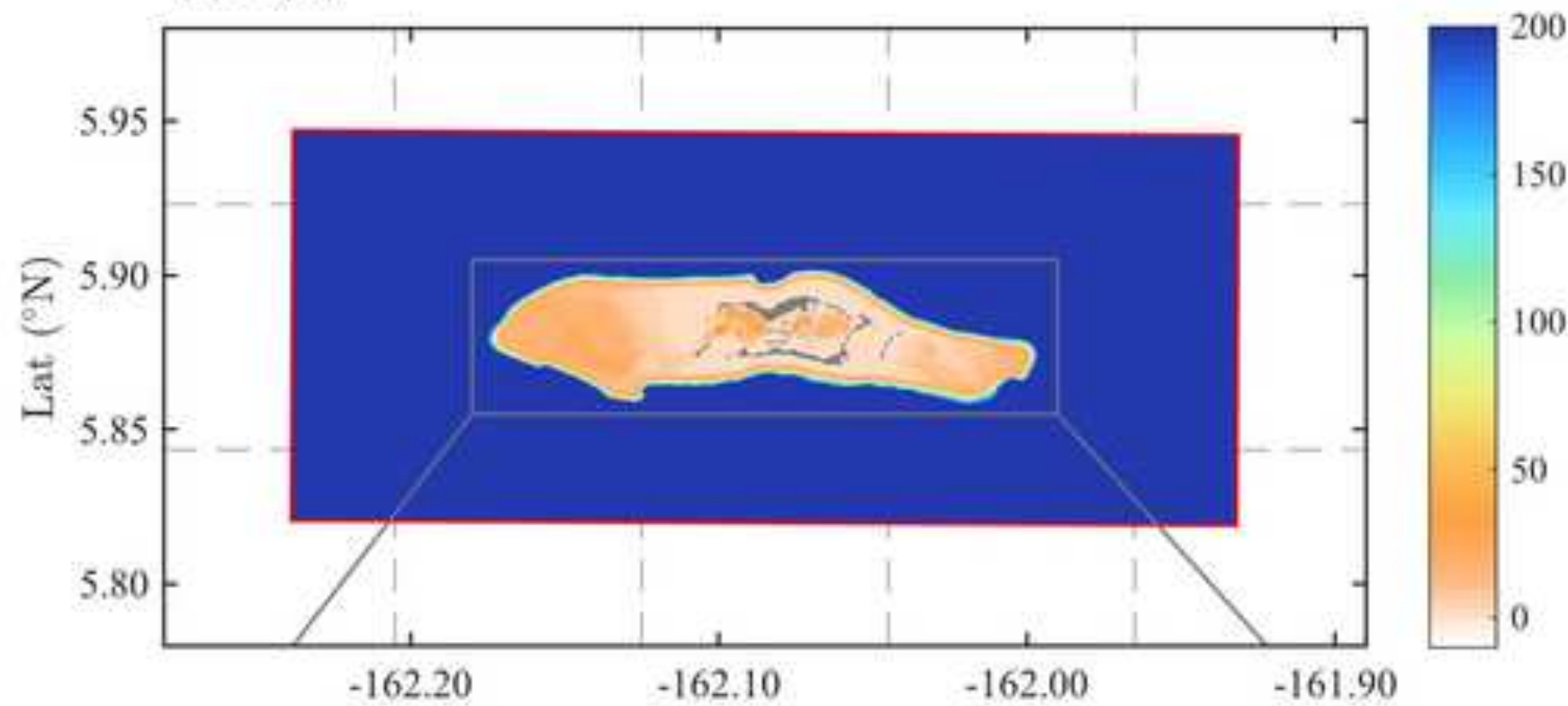

(b) $h(\mathrm{~m})$
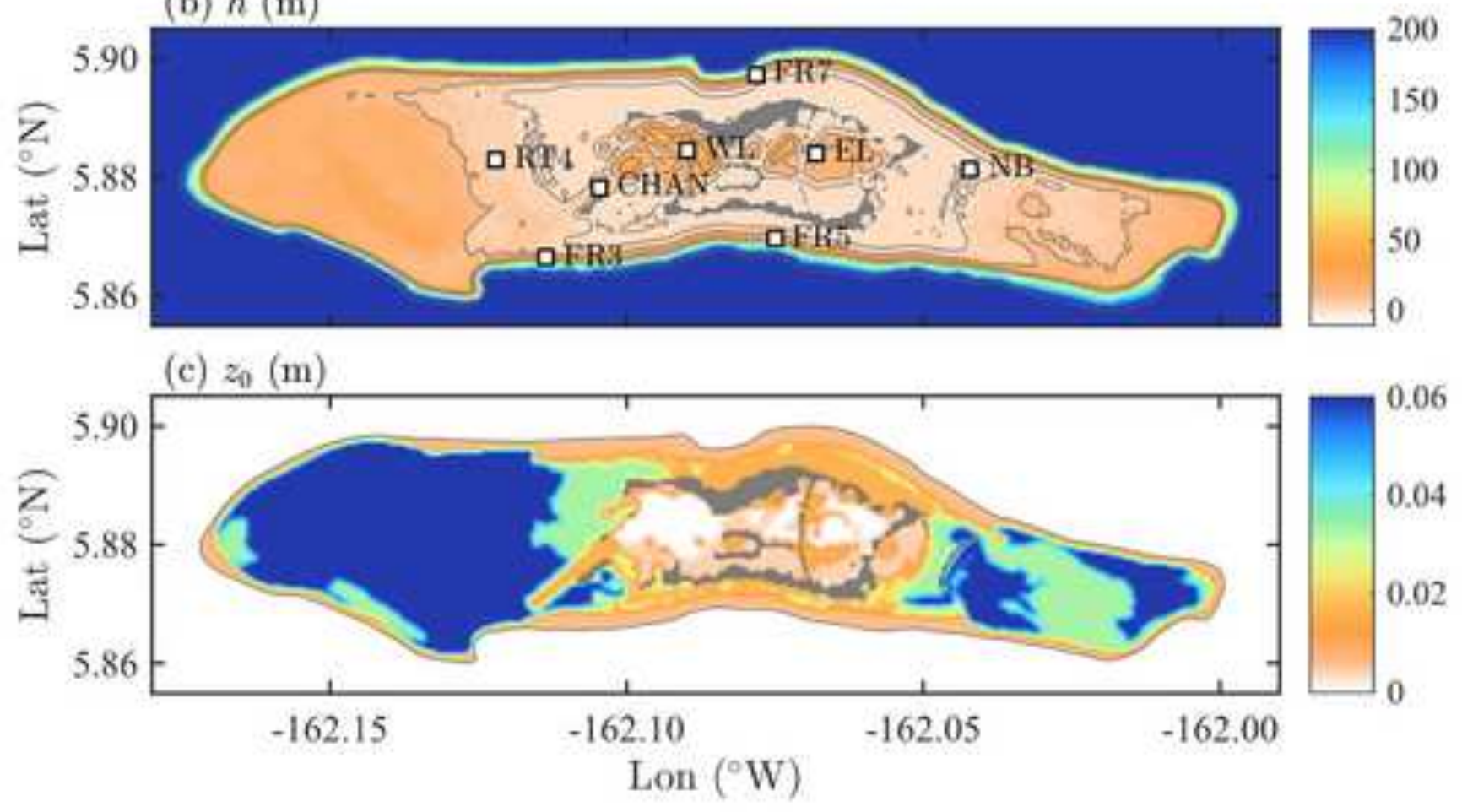

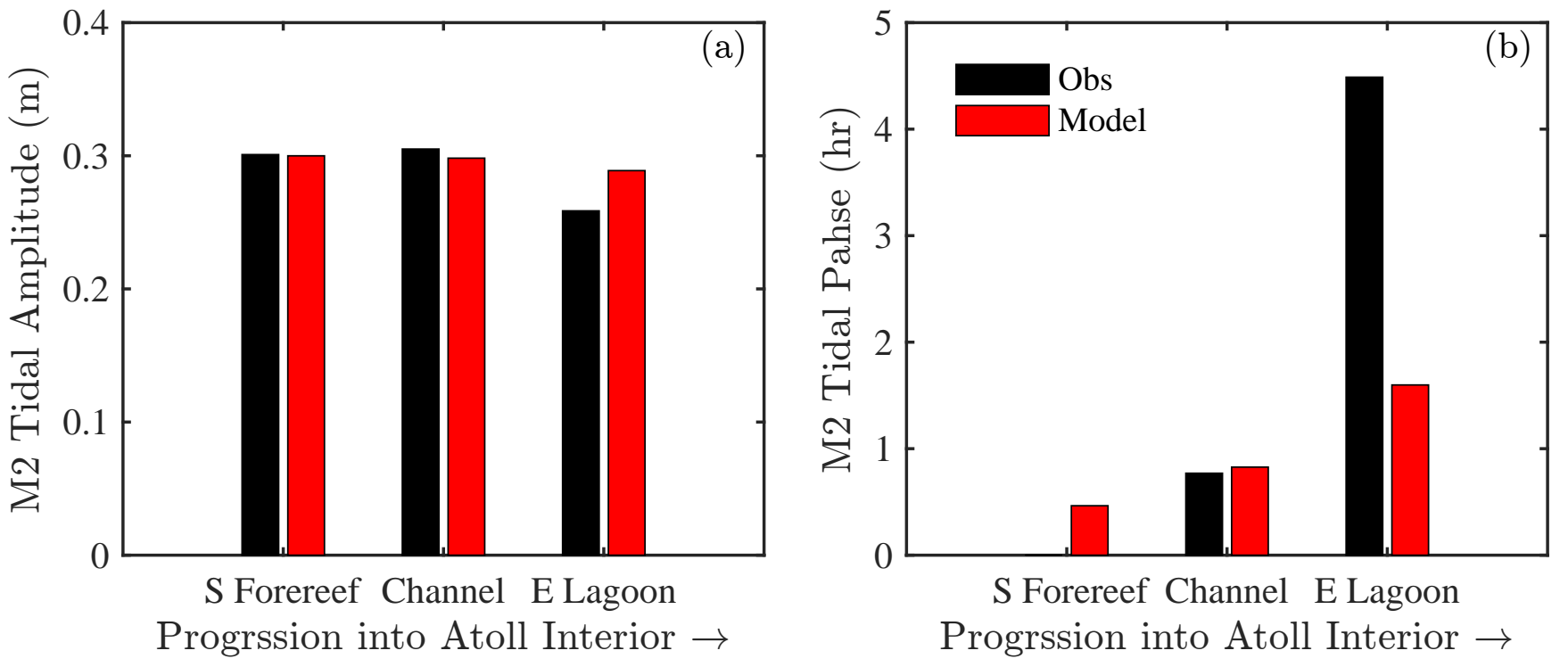

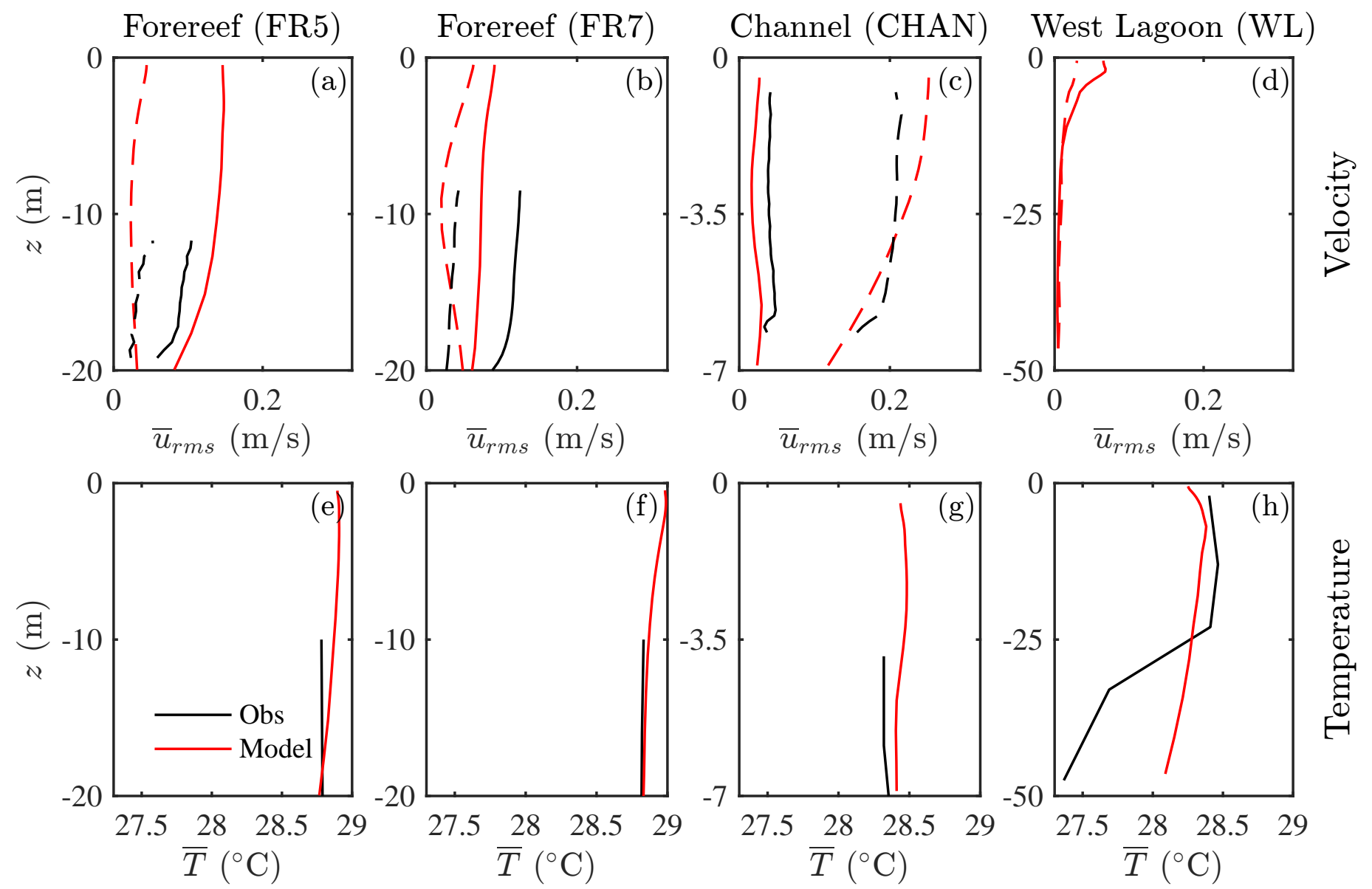

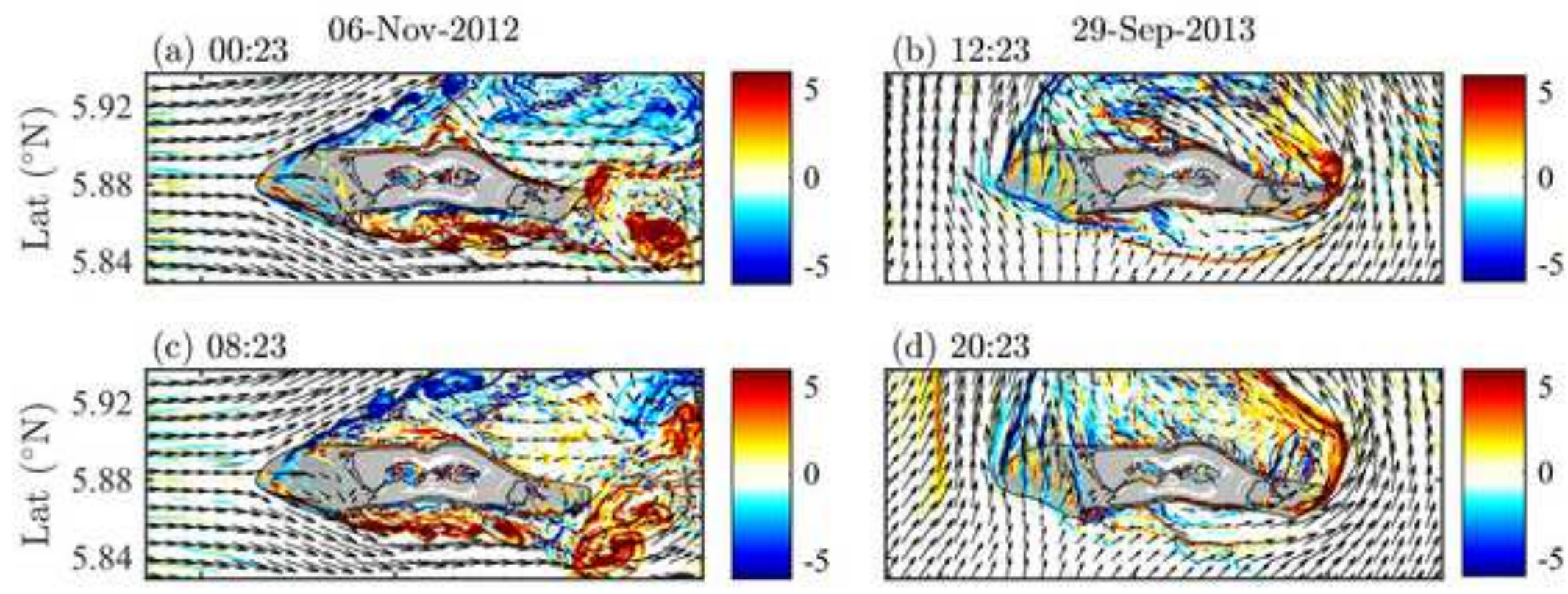

(d) 20:23

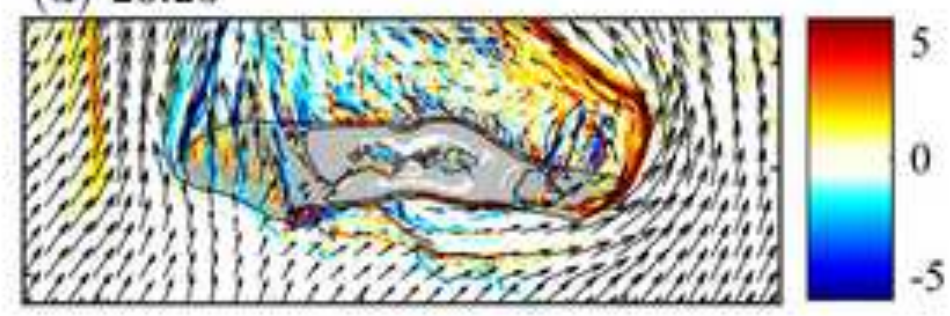

(e) 16:23
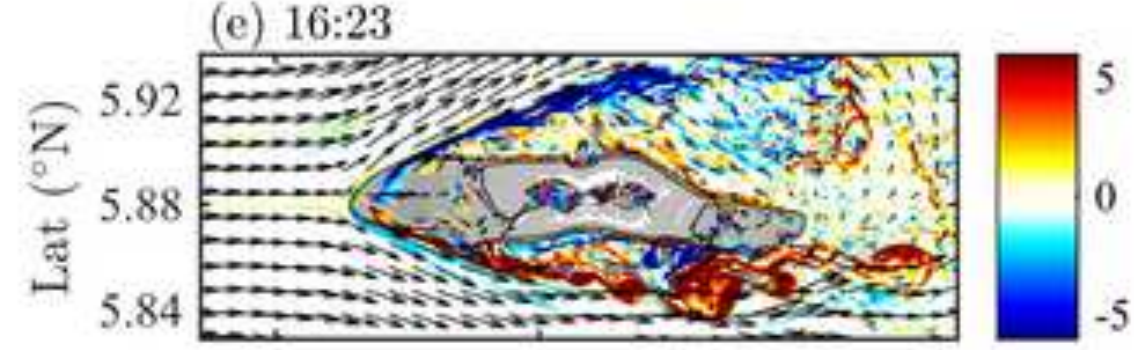

(f) $04: 23$
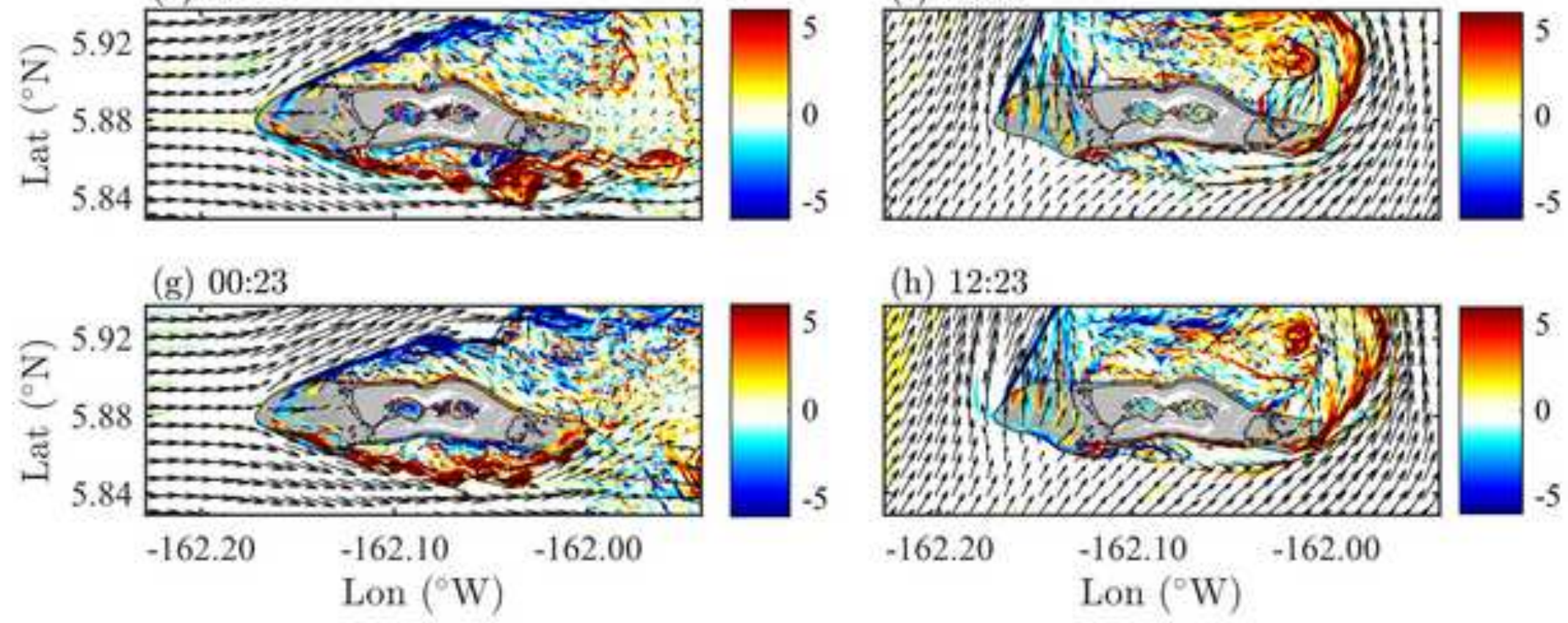

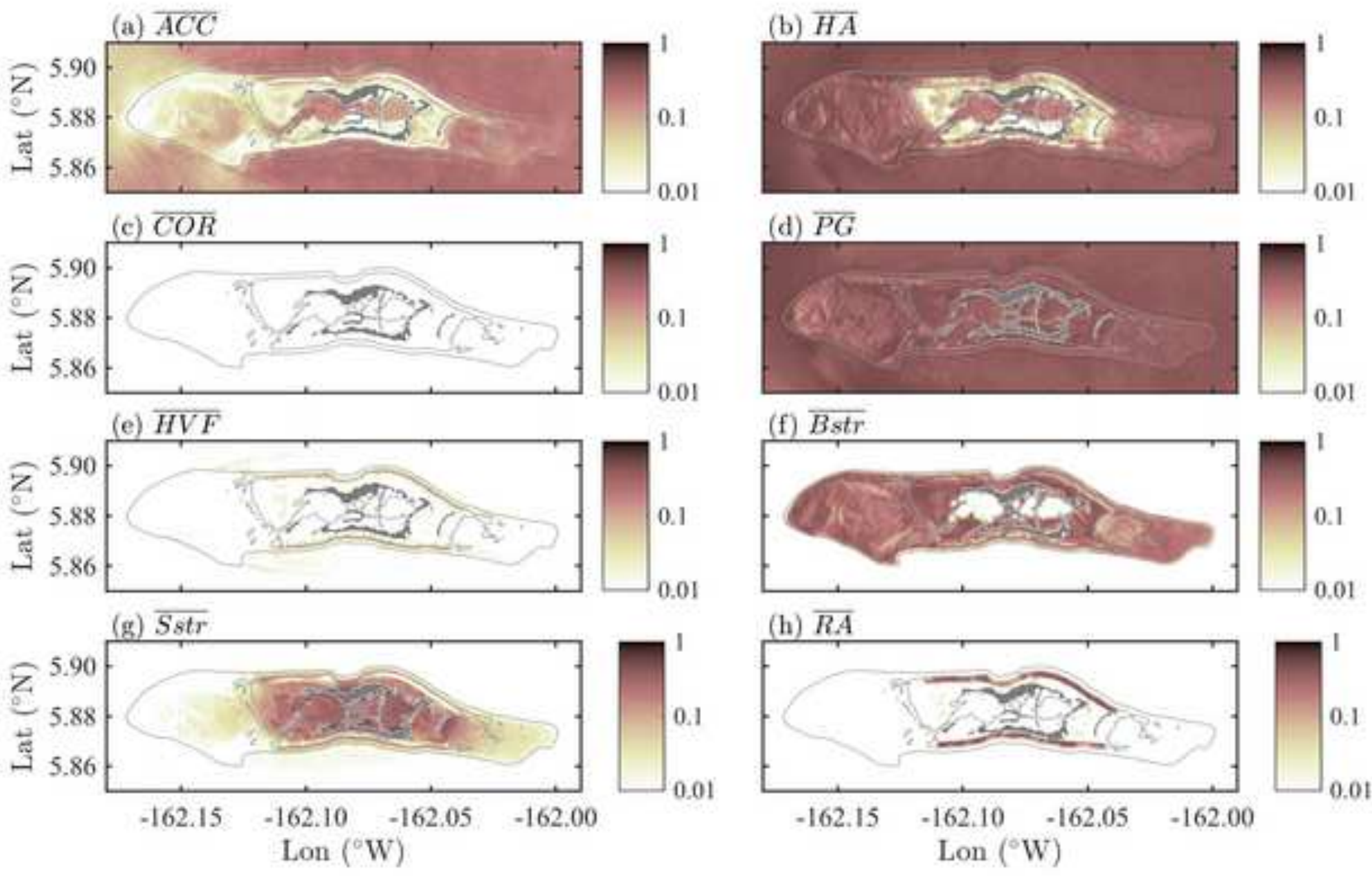

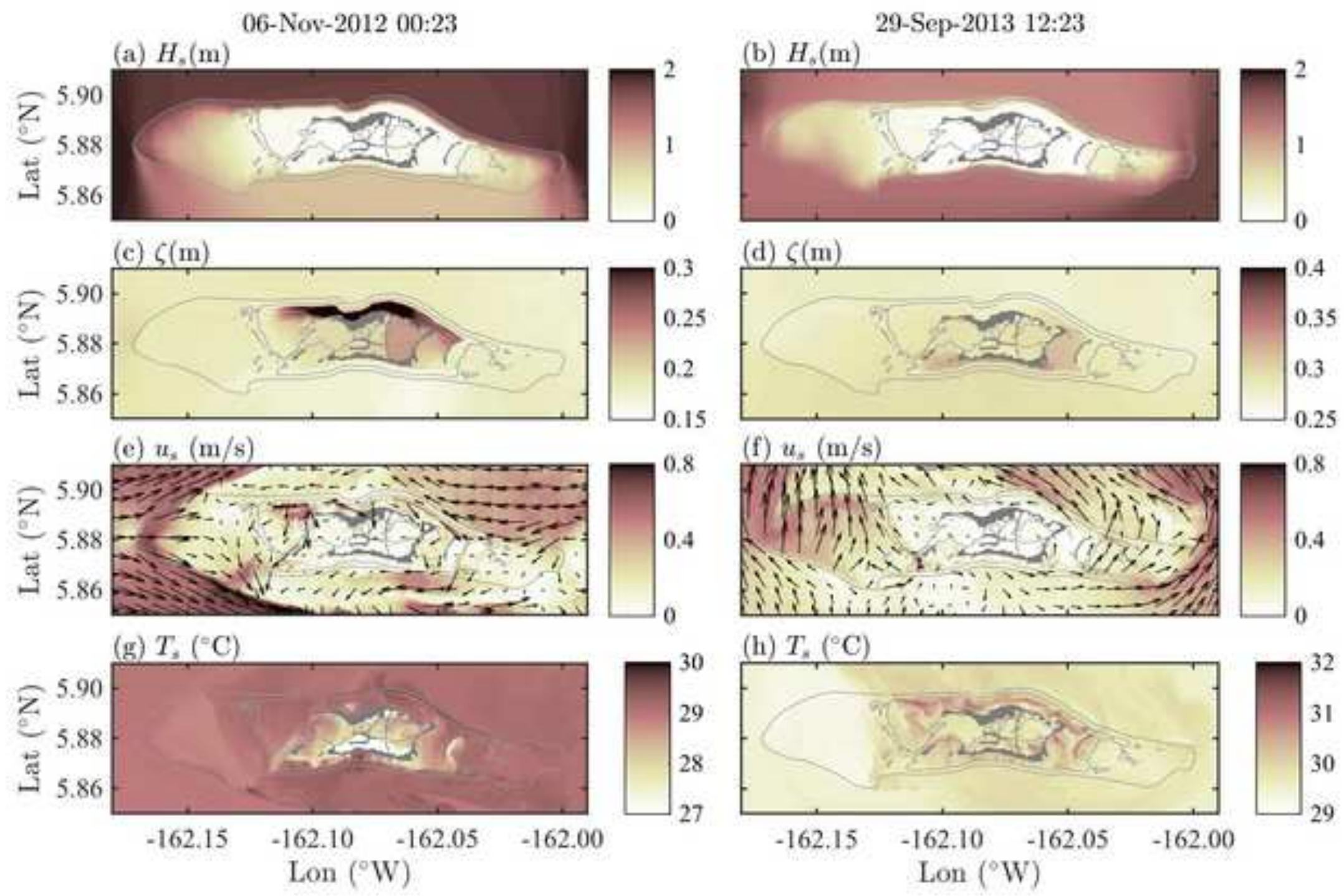


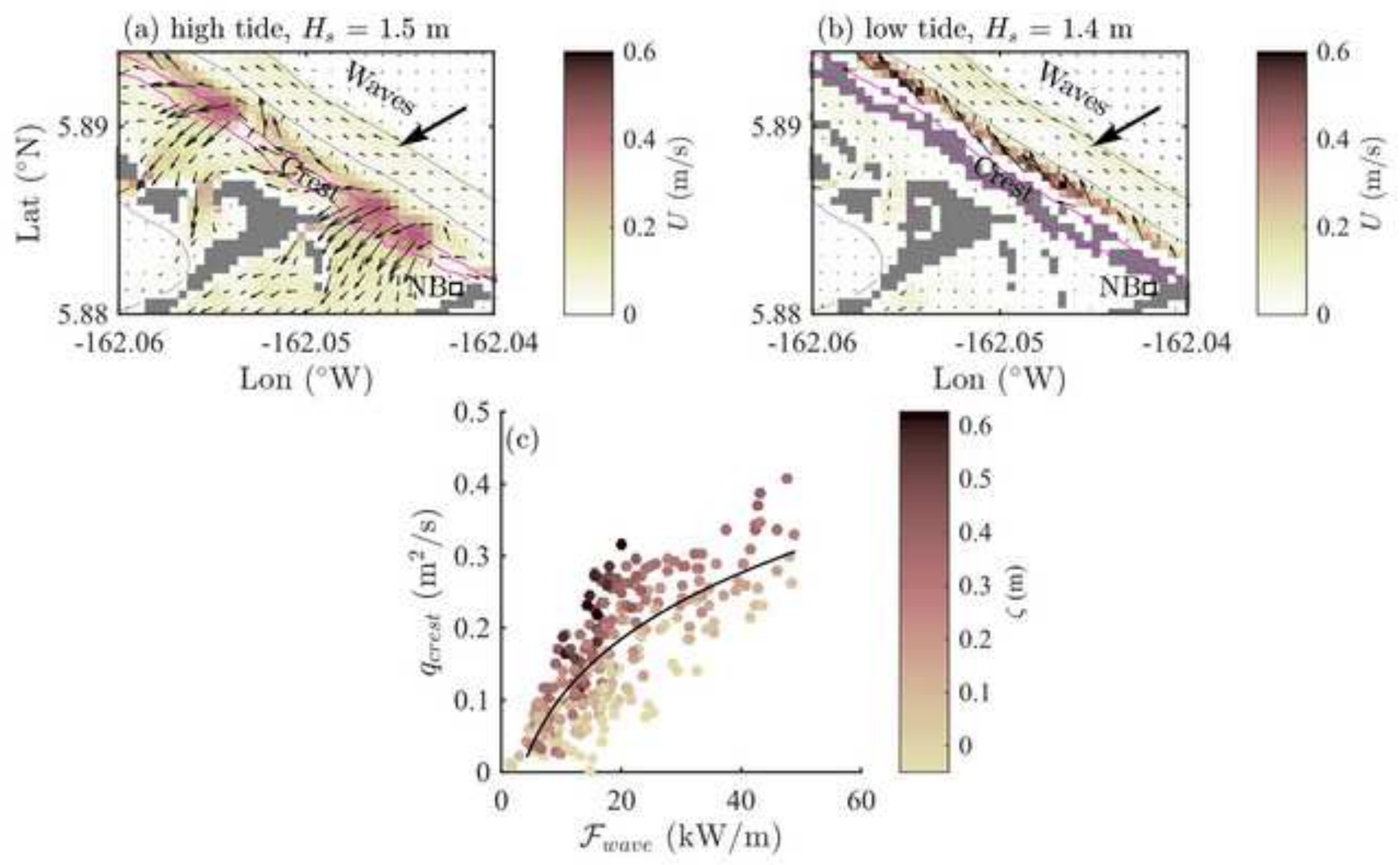



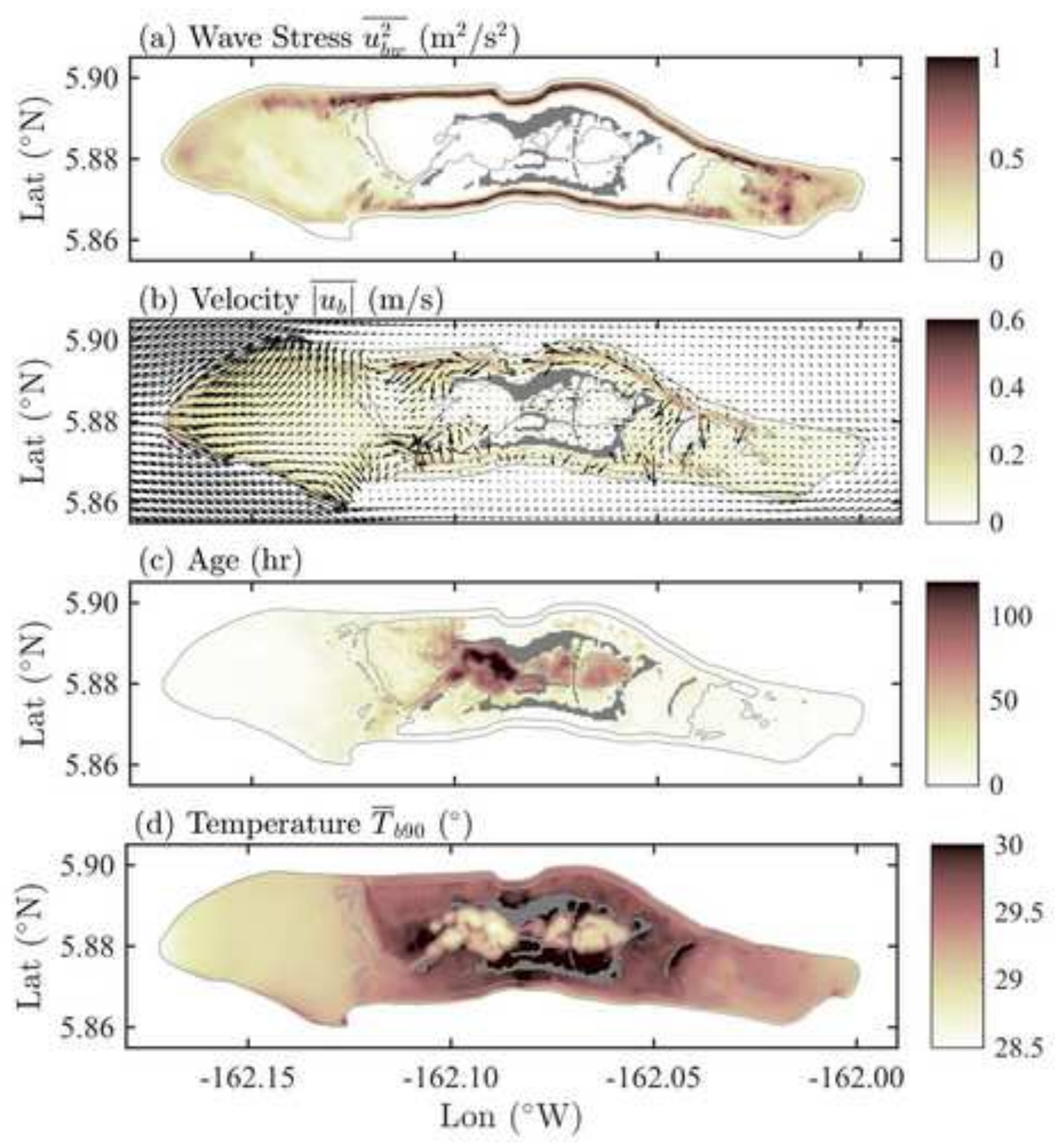

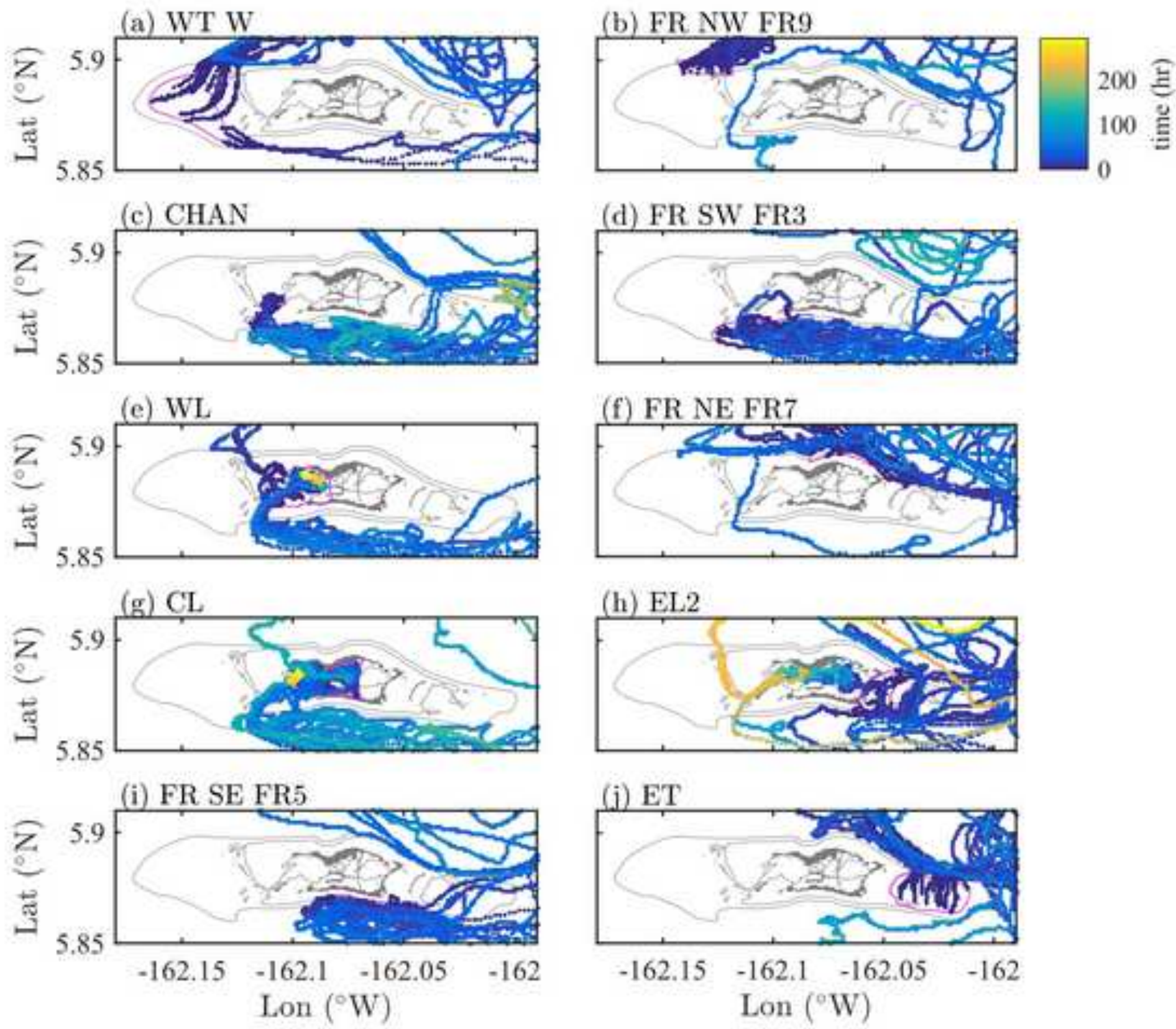
(a)

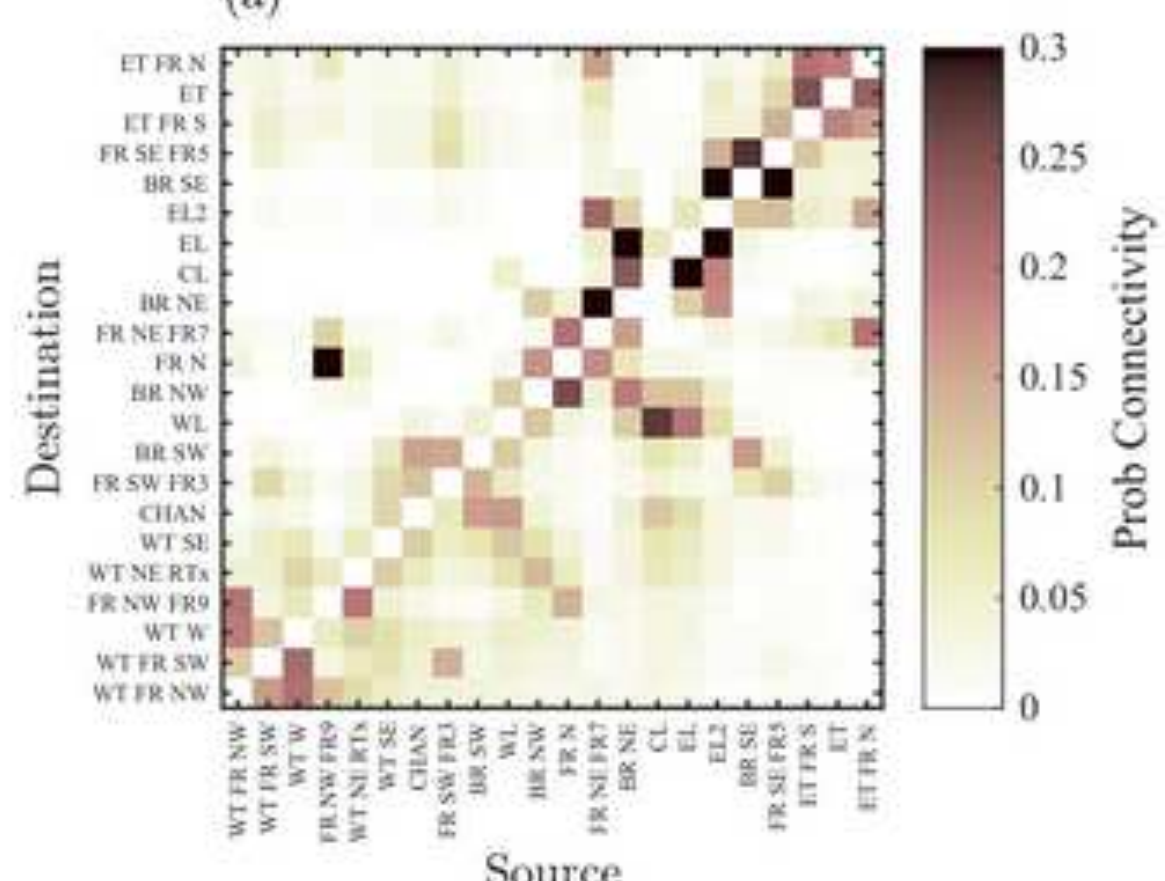

(b)
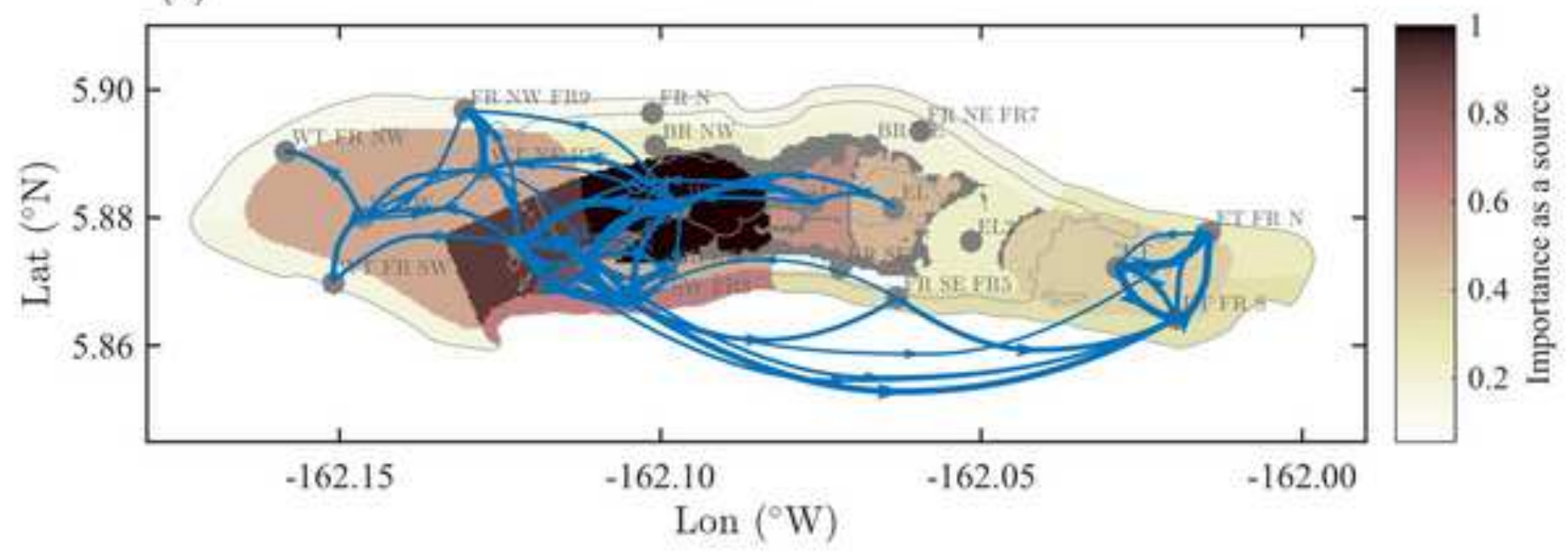

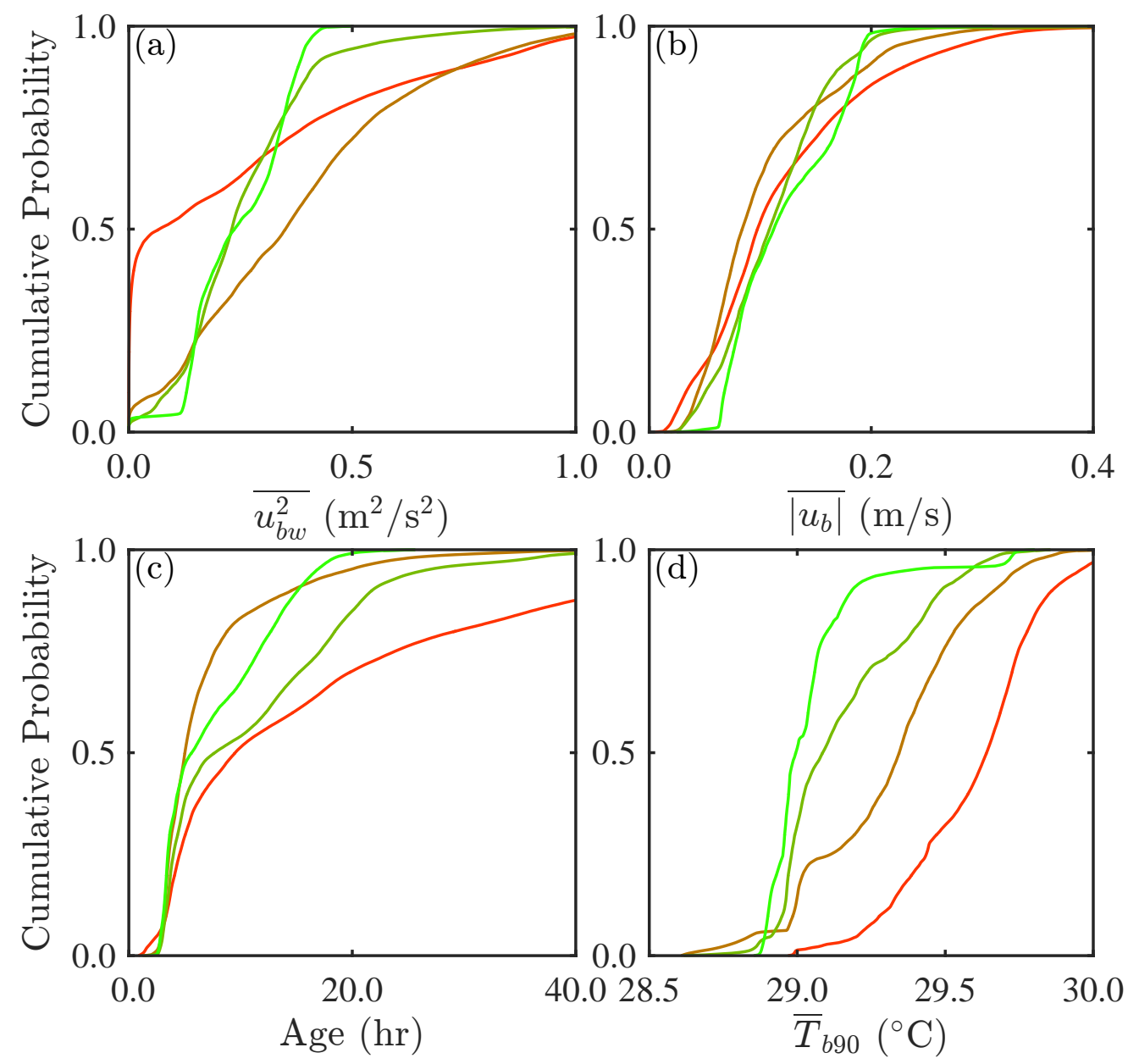

Coral $0-<10 \%$

Coral $10-<50 \%$

Coral 50-<90\%

Coral 90-100\% 